\title{
EQUILIBRIO Y CONTROL DEL PODER POLÍTICO EN LA TRADICIÓN POLÍTICA Y CONSTITUCIONAL COLOMBIANA*
}

\section{BALANCE AND CONTROL OF POLITICAL POWER IN THE COLOMBIAN POLITICAL AND CONSTITUTIONAL TRADITION}

\begin{abstract}
Sonia Patricia Cortés Zambrano Abogada Universidad Santo Tomás, Especialista en Derecho Constitucional y Derecho Parlamentario de las Universidades Externado de Colombia y Autónoma de Madrid España, Magister en Derecho Público de las Universidades Santo Tomás y Universidad de Konstanz Alemania, Doctoranda en Derecho de la Universidad Externado de Colombia, Docente Investigadora del Centro de Investigaciones Socio Jurídicas Francisco de Vitoria y Coordinadora del Semillero de Derecho Público: La Constitución y la Actividad del Estado en Colombia. E mail: soniacortes@usantotomas.edu.co y sonetzka@hotmail.com
\end{abstract}

Fecha de recepción: 28 de febrero de 2010

Fecha de aprobación: 14 de mayo de 2010

\footnotetext{
${ }^{*}$ Este artículo corresponde a un avance de la investigación que se adelanta como investigación de Tesis Doctoral.
}

\section{Resumen:}

La complejidad de las tareas políticas, ha dado origen a una especialización funcional o división del trabajo político (tridivisión del poder liberal cuyo contenido era el de limitar el poder de los gobernantes), el fin, eliminar la centralización absoluta del poder en cabeza de una sola persona o gobernante único. Nos enfrentamos a un evidenciado debilitamiento de los órganos legislativos y de los 


\section{REVISTA VIRTUAL VIA INVENIENDI ET IUDICANDI \\ "CAMINO DEL HALLAZGO Y DEL JUICIO"}

http://viei.usta.edu.co/ E-MAIL: revistainveniendi@usantotomas.edu.co

gobiernos regionales, en beneficio del acrecentamiento de las facultades del Ejecutivo, rompiéndose el esquema clásico de la igualdad y equilibrio de las ramas del poder, y haciendo más que nunca necesario el efectivo control del poder político.

Así, aunque la formalización de la independencia e igualdad de los órganos sigue haciendo parte del discurso constitucional, otra cosa sucede en la realidad política, en donde el Congreso, ostenta un carácter formal, por oposición al Ejecutivo, al cual se siguen atribuyendo un sin número de funciones que aumentan su poder. Se trata pues de verificar un posible debilitamiento del órgano Legislativo, en contraposición con la amplísima facultad decisoria del Gobierno.

El análisis abarca el problema de la naturaleza histórica del precepto de separación de competencias de las Ramas del Poder Público, intentando comprender la realidad estatal como proceso, lo que constituye uno de los aspectos centrales del constitucionalismo actual, el propósito aquí es analizar la relación entre disposiciones constitucionales de control político, con la manera como se desarrollan las relaciones entre Ejecutivo y Legislativo, y cómo influyen de manera directa en la forma como se ejerce el poder político en Colombia. 


\section{REVISTA VIRTUAL VIA INVENIENDI ET IUDICANDI \\ "CAMINO DEL HALLAZGO Y DEL JUICIO"}

http://viei.usta.edu.co/ E-MAIL: revistainveniendi@usantotomas.edu.co

\section{Abstrac:}

The complexity of the political tasks, has led to functional specialization or division of the political (power tridivisión liberal whose content was to limit the power of rulers), in order to eliminate the absolute centralization of power in head of a single person or single ruler. We face an evident weakening of the legislature and regional governments, benefiting from enhanced executive powers, breaking the classic pattern of equality and balance of the branches of power, and doing more than ever necessary to the effective control political power.

Thus, while the formalization of independence and equality of organs continues to share with the Constitution, nothing really happens in politics, where Congress holds a formal character, as opposed to the Executive, which is still without attributing a number of features that increase their power. It is therefore verify a possible weakening of the legislature, as opposed to the vast power of decision of de government.

The analysis covers the problem of the historical nature of the precept of separation of powers of the branches of government, trying to understand reality as a process state, which is one of the central aspects of current constitutionalism, the purpose here is to analyze the relationship between constitutional provisions for political control, with the way relationships develop between the executive and 


\section{REVISTA VIRTUAL VIA INVENIENDI ET IUDICANDI \\ "CAMINO DEL HALLAZGO Y DEL JUICIO"}

http://viei.usta.edu.co/E-MAIL: revistainveniendi@usantotomas.edu.co

legislative, and how to have a direct impact on how political power is exercised in Colombia.

\section{Palabras clave:}

Control del Poder Político, Equilibrio del Poder Político, Constitución, Estado de Derecho, División funcional del Poder, Hiperpresicencialismo, Ramas del Poder Público.

\section{Key words:}

Control of political power, balance of political power, Constitution, State of low, Functional division of power, Hiperpresidencialism.

\section{Identificación del Artículo:}

Avance de Investigación 


\section{REVISTA VIRTUAL VIA INVENIENDI ET IUDICANDI \\ "CAMINO DEL HALLAZGO Y DEL JUICIO"}

http://viei.usta.edu.co/ E-MAIL: revistainveniendi@usantotomas.edu.co

\section{EQUILIBRIO DE PODERES EN LA TRADICIÓN POLÍTICA Y CONSTITUCIONAL}

Los acontecimientos históricos, políticos, económicos y sociales, han permitido observar cómo se transforma la concepción del Principio de Separación de Poderes. No solo el poder legislativo hace las Leyes, también las hace el Ejecutivo y el Judicial. En el proceso de formación de la ley concurre, bien sea por iniciativa, en su tramitación, en el planteamiento o resolución de las objeciones el Ejecutivo, y en el proceso de Constitucionalidad de la Ley la Corte Constitucional actúa como Legislador Negativo, y son sus sentencias derogatorias de Ley, o cuando da órdenes al legislativo o al ejecutivo de cómo actuar o legislar. Por su parte el Congreso ejerce tareas administrativas, como los nombramientos de quienes ejercen el control político, lo que deja entrever que el principio de separación de poderes inicialmente concebido ha sufrido tal impacto que no tiene ya valor en su sentido primero.

Fenómeno de la Complejidad en las relaciones de poder: cómo separar algo que es uno, el Estado, los tres poderes del Estado con funciones y competencias constitucionales propias. El Control es un elemento inseparable de concepto de Constitución, y ello se evidencia en la institucionalización de los controles, la concepción pluralista de poder, la democracia y su fuerte vínculo con la opinión pública. 


\section{REVISTA VIRTUAL VIA INVENIENDI ET IUDICANDI \\ "CAMINO DEL HALLAZGO Y DEL JUICIO" \\ http://viei.usta.edu.co/ E-MAIL: revistainveniendi@usantotomas.edu.co}

\section{Principio de Separación del Poder en la tradición constitucional.}

La teoría de separación de poderes, promueve en sí misma el concepto normativo de la Constitución, esta naturaleza normativa de la Constitución se entiende en el sentido de que es en la Constitución positiva donde deben buscarse las garantías de su propia vigencia efectiva. La teoría del poder constituyente lo delimita en la legitimación popular, por medio de mecanismos y normas procedimentales que encausan normativamente su actuación, esto sin embargo no garantiza la racionalidad de la Constitución Positiva., y que en el funcionamiento del poder constituyente no entren en juego factores históricos que relativicen su eficacia. Lo que sí puede analizarse racionalmente, es el objetivo que en ella se establece y el modo como se organiza su realización en relación con la libertad de los individuos. En la relación entre un momento social y un momento político, como elementos constitutivos de un proceso de desarrollo de las relaciones sociales a partir de los intereses de los individuos, el Estado actúa como mediador entre ambos momentos, para asegurar una solución racional al conflicto de intereses. En éste contexto la Constitución, es el instrumento concreto que garantiza la aplicación general del derecho en las relaciones sociales y la posibilidad de su revisión política. (DE AGAPITO SERRANO 1989).

La interpretación del principio de separación de poderes apunta a la necesidad teórica de replantear la orientación general del Estado, lo que está en estrecha 


\section{REVISTA VIRTUAL VIA INVENIENDI ET IUDICANDI \\ "CAMINO DEL HALLAZGO Y DEL JUICIO" \\ http://viei.usta.edu.co/E-MAIL: revistainveniendi@usantotomas.edu.co}

relación con la recuperación de la relevancia constitucional del proceso político. Los límites constitucionales del proceso político, hacen referencia a la vigencia jurídica de los derechos fundamentales, como a la vinculación material del proceso político a ellos, a través de un concepto adecuado de la representación política. A ello se debe la importancia de recuperar el sentido pleno de la función de la legislación respecto de las demás funciones del Estado. Si no se regula adecuadamente el proceso político, la vigencia de los derechos fundamentales, puede debilitarse al depender su realización ya de una política sectorizada obediente a unos intereses globales, desde los distintos grupos del pluralismo social y político, ya de una defensa jurídica meramente individual. Cabe señalar que la rama judicial o poder judicial, se mantiene al margen del juego político de fuerzas entre poderes del Estado y allí podría afirmarse con propiedad que se mantiene una verdadera separación de poderes, si no fuera distinta la realidad.

No se trata de retornar a los planteamientos que presentan el legislativo como supremo, pues todas las ramas del Estado obedecen a la legitimación democrática. Debe existir una separación entre administración y proceso político. La ejecución del derecho supone condiciones de objetividad, que derivan de su aplicación a partir de los criterios de generalidad y permanencia. La primera supone un componente esencial de la seguridad jurídica y representa la existencia de un nexo social de manera que de éste puedan surgir unos intereses políticos, que concreten la necesidad de renovación del derecho. La característica 


\section{REVISTA VIRTUAL VIA INVENIENDI ET IUDICANDI \\ "CAMINO DEL HALLAZGO Y DEL JUICIO"}

http://viei.usta.edu.co/ E-MAIL: revistainveniendi@usantotomas.edu.co

fundamental de las constituciones que se refiere a la implementación de un modelo de separación y control de los poderes, es una idea democrático-liberal que se opone al monopolio del poder en un solo órgano o sujeto, promovida por Montesquieu, principio que se modifica tras la evolución y transformación en las relaciones de poder en un marco de reformas políticas y estatales que atienden a procesos globales.

Se impone la tecnocracia, el poder de la élite administrativa, donde el ejecutivo fuerte ejerce además de las labores de administración, importantes funciones propias del órgano legislativo. Más aún la Corte Constitucional puede por medio de interpretación constitucional crear legislación (Inconstitucionalidad por omisión), lo cual incrementa el poder en el poder judicial.

En Colombia, el principio de separación y equilibrio del poder ha tenido una compleja evolución, sus orígenes se remontan al establecimiento de la República, siendo acogido como pilar en las Constituciones. La importancia de éste principio se fundamenta en su capacidad de prevenir la degeneración de la república en tiranía, proteger el estado frente al absolutismo o autoritarismo. La época en la que surge y se consolida la república en América es la propicia para el fortalecimiento y la plenitud del Principio de Separación de poderes. Los postulados radicales de la ilustración de división de poder, son adoptados sin vacilaciones, por las primeras constituciones, con el objeto, a veces no próspero, 


\section{REVISTA VIRTUAL VIA INVENIENDI ET IUDICANDI \\ "CAMINO DEL HALLAZGO Y DEL JUICIO"}

http://viei.usta.edu.co/ E-MAIL: revistainveniendi@usantotomas.edu.co

de eliminar las pretensiones déspotas de los libertadores, bajo la expectativa revolucionaria que despertaba la ley, que no es otra cosa que el cambio de soberanía, que implica que antes que los hombres están las instituciones. Sin embargo, los tiempos de guerra fueron en principio los primeros factores que hicieron tambalear este Principio, mostrando su fragilidad de cara al poder de la fuerza.

Durante la guerra el poder no se separa sino que se concentra, se concentra en el ejército o en sus líderes, es así como los fundadores de la República fueron generales. Con el tiempo éste principio ha sufrido un desgaste, para algunos notables desajustes o simples transformaciones. De la separación firme y radical, inspirada en la revolución y la libertad, se pasa a una simple enunciación de los órganos del poder en torno a la ley, se llega a un Estado en donde el Ejecutivo, por medio de la iniciativa legislativa, las objeciones, y la sanción de las leyes, abre la puerta a que ya este principio político constitucional, no sea analizado en su estricta configuración primera, ya que la función de legislar no le está permitida solo al Congreso sino también a los demás poderes del Estado lo cual evidencia una clara desproporción entre lo instituido y la realidad.

La comprensión teórica del principio de equilibrio, de pesos y contrapesos en el ejercicio del poder político, debe tener en cuenta hoy la complejidad de la realidad social y la configuración normativa de la orgánica del Estado. Hoy este principio 


\section{REVISTA VIRTUAL VIA INVENIENDI ET IUDICANDI \\ "CAMINO DEL HALLAZGO Y DEL JUICIO"}

http://viei.usta.edu.co/ E-MAIL: revistainveniendi@usantotomas.edu.co

debe incluir otros aspectos más allá de las funciones tradicionales del Estado, su necesaria colaboración y su recíproco control. Debe analizarse en conjunto el dualismo entre legislador constituyente y legislador ordinario, la división interna de los órganos superiores del Estado: el legislativo en cámara de representantes y senado, o dentro del ejecutivo entre órganos políticos y Burocracia. Debe igualmente involucrarse la Administración que atada a las funciones del ejecutivo refuerza la posición de éste sobre las demás funciones del Estado, centralizando la acción del Estado, éste proceso genera a su vez la necesidad de incrementar el control de la actividad de la administración. El control puede ejercerse a través de la regulación de los procedimientos en la toma de decisiones, y de los mecanismos para sus impugnaciones, a través de la participación ciudadana en tales procesos de formación de las decisiones, o incluso mediante la descentralización cuyo alcance rebasa el ámbito meramente administrativo para llegar a formular una autonomía de naturaleza netamente política.

Por su parte la función de Control de constitucionalidad, parece rebasar el esquema y la aceptación teórica originarios de la división de poderes, pero al mismo tiempo plantea unos nuevos problemas de definición y delimitación de las distintas funciones superiores del Estado. La evolución del principio tiene su razón en las necesidades concretas de las sociedades complejas y contienen un desarrollo de la idea de Estado Constitucional, en la medida en que incorporan y amplían garantías frente a la posible arbitrariedad del Estado, pese a ello no 


\section{REVISTA VIRTUAL VIA INVENIENDI ET IUDICANDI \\ "CAMINO DEL HALLAZGO Y DEL JUICIO"}

http://viei.usta.edu.co/ E-MAIL: revistainveniendi@usantotomas.edu.co

debemos rendirnos ante ésta complejidad práctica como si en ella se consumara un desarrollo lineal o cuantitativo del Estado Constitucional. Existen indicios suficientes para determinar que ésta complejidad práctica se paga al precio de un empobrecimiento teórico de del sentido racional originario del principio de División de Poderes y que ello se refleja en la pérdida de claridad en lo que refiere a la definición y delimitación de funciones superiores del Estado, un hecho que en el constitucionalismo actual, contrae el concepto de Estado y en particular del principio de separación de poderes, el cual se diluye para aparecer como un principio difuso cuyo contenido se reduce al criterio genérico de una limitación del poder del Estado.

El derecho en general y la Constitución en particular, se encuentran atados a una interpretación, la doctrina señala que el alcance de ésta interpretación se concreta en el desarrollo positivo de los contenidos de las normas y en particular la interpretación de la Constitución, ya no solo se centra en las posibles trasgresiones procedentes de la actividad del Estado incluida la elaboración de las leyes, la evolución del Estado Constitucional puede interpretarse, como un desarrollo en el que los poderes del Estado se someten al Derecho, en particular el poder legislativo. El Estado pierde así su omnipotencia inicial para someterse a la Constitución de lo cual se deduce y fundamenta la instauración del control jurisdiccional de las leyes. Se acentúa la dimensión política de la constitución como el instrumento adecuado para reducir el poder social que existe en una 


\section{REVISTA VIRTUAL VIA INVENIENDI ET IUDICANDI \\ "CAMINO DEL HALLAZGO Y DEL JUICIO" \\ http://viei.usta.edu.co/ E-MAIL: revistainveniendi@usantotomas.edu.co}

determinada sociedad. En la actualidad la interpretación d la Constitución, insiste en la permanencia del texto constitucional y la existencia de mecanismos jurídicos que garanticen su vigencia y que aseguren su adecuación a la evolución de las relaciones sociales. La falta de integración de los componentes jurídicos y políticos de la constitución puede contribuir a favorecer una vigencia formal, abierta a una orientación coyuntural de la norma fundamental, generando serias dificultades para determinar cuando se trata de desarrollo constitucional o cambio de constitución.

La Constitución debe ser entendida en su sentido finalista, en la medida que incluye un objetivo constitucional históricamente concreto y en este sentido se justifica la definición orgánica del Estado que articula la estructura constitucional (delimitación de las funciones superiores del Estado) con una superposición diferenciada en ella del proceso político (relación pacífica entre las fuerzas sociales). La falta de claridad acerca de lo que constituye el núcleo esencial del principio de separación funcional y equilibrio entre las relaciones de poder entre las ramas del poder público, da pie a críticas sobre la situación actual que refleja acuerdos extra-constitucionales entre fuerzas políticas y sociales o la manera como las instancias de control constitucional interfiere en el funcionamiento de otros órganos del Estado. Debemos integrar la concepción de la naturaleza jurídica de la constitución con el sentido político de ésta, y para ello se debe desarrollar inicialmente la concepción política de la Constitución. 


\section{REVISTA VIRTUAL VIA INVENIENDI ET IUDICANDI \\ "CAMINO DEL HALLAZGO Y DEL JUICIO" \\ http://viei.usta.edu.co/ E-MAIL: revistainveniendi@usantotomas.edu.co}

El diseño práctico de la organización del Estado, es un componente inherente a la idea de división funcional de las ramas del poder público. La Constitución tiene un sentido político, ya que su propósito es orientar y encauzar el tránsito de una sociedad hacia otra definida por la vigencia general de la libertad concreta que constituye su objeto jurídico- fundamental. Para lo cual incorpora contenidos jurídicos de tipo material y organizatorio que responda al conflicto histórico y social existente en la sociedad. (DE AGAPITO SERRANO 1989) La Constitución incorpora siempre unos contenidos jurídicos históricos y por lo tanto tiene un sentido político, el cual refleja el nivel general de libertad social que se postula negativamente frente a las formas anteriores, y que permite mantener presente el carácter relativo de éste nivel de libertad, por referencia a las realidades que aún no se acogen en ella. La Vigencia de la Constitución, incluye junto al aspecto de seguridad jurídico-constitucional, la realización política de los derechos fundamentales, siendo éste el medio calve para verificar la generalidad de la concreción de éstos en el derecho ordinario, hasta que de ellos se impregnen todos los ámbitos de la sociedad.

La Separación del poder, que tiene como objeto el evitar que el poder degenere en tiranía, irá con el tiempo sufriendo un progresivo desgaste y notable desajuste, de la separación firme y radical, se pasa a una simple enunciación de los órganos del poder, con la tenue afirmación de que cada uno lo ejercerá en los términos que la Constitución establece. De la Simplificada visión de la división del poder en torno a 


\section{REVISTA VIRTUAL VIA INVENIENDI ET IUDICANDI \\ "CAMINO DEL HALLAZGO Y DEL JUICIO"}

http://viei.usta.edu.co/ E-MAIL: revistainveniendi@usantotomas.edu.co

la ley, se llegará al desajuste que supone el concurso del ejecutivo, por medio de la iniciativa, las objeciones y la sanción en la tramitación de la ley, lo cual supone que la función legislativa, ya no corresponde solo al legislativo, lo cual desdibuja la realidad de la separación de poderes. Es innegable la complejidad en el ejercicio del poder y es ésta complejidad la que transforma desde su base, el principio de separación de poder. Más allá de las breves pausas de los gobiernos que se dieron al margen de la Constitución, como ocurrió con las dictaduras del General Reyes y del General Rojas Pinilla, la introducción constitucional de las facultades extraordinarias y el Estado de Sitio, permitieron al ejecutivo legislar, incluso de manera permanente. La formación de la ley ya no corresponde solo al legislativo, pues el ejecutivo pude realizar esta función e incluso el judicial, con ocasión al control de constitucionalidad de las leyes (legislador negativo).

Sin duda la Constitución de 1991 modificó radicalmente el sistema de separación de poderes, la rigidez de la regla es matizada por la actividad política, de tal manera que si logramos esquematizar el proceso político, lograremos encontrar un sentido a la separación de poderes. 


\section{REVISTA VIRTUAL VIA INVENIENDI ET IUDICANDI \\ "CAMINO DEL HALLAZGO Y DEL JUICIO"}

http://viei.usta.edu.co/ E-MAIL: revistainveniendi@usantotomas.edu.co

\section{b. El equilibrio y control del poder en la Constitución Política de la República de Colombia de 1991}

El artículo 113 de la Constitución, con el cual se inicia el capítulo de la estructura del Estado, señala un primer elemento, se mantiene la división del poder público solo en las tres ramas clásicas. Sin embargo, las funciones legislativa, ejecutiva y judicial, son complementadas con otras a cargo de órganos autónomos independientes de las tres ramas. La Constitución denomina órganos de control al Ministerio Público, y a la Contraloría general de la república (artículo 117 C.P.), y organismos electorales a los encargados de organizar, dirigir y vigilar las elecciones (artículo 120 C.P.), No hay cinco ramas sino cinco funciones diferentes. La distribución de las funciones en las tres ramas y los órganos independientes, son separadas, y como es tradición constitucional, el presidente en circunstancias excepcionales puede legislar, y el Congreso ha sido fortalecido en sus poderes legislativos, económicos y de control político. Al observarse uno de los aspectos más importantes de la Separación de Poderes: la relación entre las tres ramas del poder público, el panorama constitucional de 1991 es significativamente distinto al que operaba antes de la Asamblea Nacional Constituyente, que originó la Constitución Política de 1991. Se conciben tres modelos de relación entre los poderes. 


\section{REVISTA VIRTUAL VIA INVENIENDI ET IUDICANDI \\ "CAMINO DEL HALLAZGO Y DEL JUICIO"}

http://viei.usta.edu.co/ E-MAIL: revistainveniendi@usantotomas.edu.co

- Las relaciones entre las ramas se caracterizan por un sistema de pesos y contrapesos dentro de la línea Madisoniana clásica imperante en los Estados Unidos.

- El sistema de la colaboración armónica, introducido formalmente en Colombia en la reforma de 1936, como ya se señaló. Recogiéndose las ideas de Wilson y Roosvelt, sobre el replanteamiento del sistema Madison de frenos y contrapesos, para hacer más eficiente y responsable al Estado, que debía intervenir en la economía e impulsar políticas sociales.

- Sistema de relaciones de Concurrencia, en el cual más de una rama participa en el desarrollo de una misma actividad o decisión. (CEPEDA 1993) La relación plasmada en la Constitución de 1991, tiene elementos de los tres sistemas al mismo tiempo. El principio de colaboración armónica se destaca en el artículo 113 de la Constitución Política, y predomina en asuntos de intervención del Estado en la economía, teniendo en cuenta que los fines del Estado deben estar orientados a la colaboración armónica, artículo 2 de la Constitución de 1991.

En materia de frenos y contrapesos, se mantiene constitucionalmente la objeción presidencial a los proyectos de ley, se fortaleció el poder judicial de revisar la constitucionalidad de los actos de las ramas del poder público. En cuanto a la Concurrencia entre poderes, se presentan las mayores innovaciones con la 


\section{REVISTA VIRTUAL VIA INVENIENDI ET IUDICANDI \\ "CAMINO DEL HALLAZGO Y DEL JUICIO"}

http://viei.usta.edu.co/ E-MAIL: revistainveniendi@usantotomas.edu.co

adopción de la moción de censura, contra los ministros, con los nuevos poderes del Senado, en materia de Estados de Excepción y de convocatoria de consultas populares, así como la institución de la pérdida de investidura de congresista decretada por un órgano judicial (Consejo de Estado). Es en torno a éstas relaciones específicas que se hace la investigación, en torno concretamente a la usurpación de competencias, y fortalecimiento de algunos de los poderes públicos sobre los demás, vulnerando principios democráticos y constitucionales más aún cuando se habla de la incorporación de un sistema mixto en el que la Concurrencia entre poderes fortalece la colaboración armónica o estimula el sistema de frenos y contrapesos, con el único objetivo de solucionar el desequilibrio atribuido a un excesivo presidencialismo, o a por el contrario estimula su fortalecimiento a punto de convertirse en un HIPERPRESIDENCIALISMO.

El nuevo esquema de separación de poderes tiene otros aspectos relevantes y que guardan con él, estrecha relación. En primer lugar el catálogo de derechos fundamentales. Las garantías fundamentales permiten que las ramas del poder público tengan un espacio más amplio de trabajo conjunto en la realización de los fines del Estado, ya que cuando éste ponga e peligro las libertades, la persona vulnerada podrá invocar el derecho fundamental evitando abusos y excesos. Igualmente las reformas electorales, por ejemplo la segunda vuelta en la elección presidencial, abre una posibilidad de coalición de minorías políticas, lo cual presiona al ejecutivo para que en su composición se refleje la coalición 


\section{REVISTA VIRTUAL VIA INVENIENDI ET IUDICANDI \\ "CAMINO DEL HALLAZGO Y DEL JUICIO"}

http://viei.usta.edu.co/E-MAIL: revistainveniendi@usantotomas.edu.co

mayoritaria, coincida o no con la del congreso, además la elección popular del vicepresidente puede estimular la coalición entre minorías. El gran interrogante es como la elección del ejecutivo incidirá en las relaciones de éste con el Congreso, donde están las principales fuerzas que compiten por controlar al ejecutivo. Las elecciones separadas de ejecutivo y legislativo, buscan dar fluidez a las relaciones entre ellos. Por su parte los instrumentos de democracia Directa o Semi-directa intervienen en el nuevo esquema de separación de poderes (referendo, plebiscito, consulta popular, iniciativa popular, revocación del mandato de alcaldes y gobernadores y la solicitud ciudadana de la pérdida de investidura de Congresista), la consulta popular en especial, que versaría sobre asuntos de trascendencia nacional, cuya convocatoria corresponde al presidente, respondería a una relación de enfrentamiento entre el Ejecutivo y el Legislativo no superada, constituyéndose así en una pieza clave de la nueva relación entre las ramas del poder público.

Aspectos de la Política Real que alteraron sustancialmente, el esquema de separación de poderes o de las ramas del poder político

Al hablar de poderes se hace referencia a las instituciones legislativa, ejecutiva y judicial: Ramas del Poder Público, atendiendo al carácter único del poder político, al cual corresponden las tres funciones básicas relegislar, ejecutar, y juzgar, por medio de órganos distintos.(ECHEVERRI 2002) El fundamento de la concepción 


\section{REVISTA VIRTUAL VIA INVENIENDI ET IUDICANDI \\ "CAMINO DEL HALLAZGO Y DEL JUICIO"}

http://viei.usta.edu.co/ E-MAIL: revistainveniendi@usantotomas.edu.co

jurídica del Estado, está constituido por el reconocimiento de éste como una unidad. El concepto de Estado según la escuela del derecho natural, obedecía a la concentración de todo el poder de aquel en una sola voluntad, se trate de una persona física o de un cuerpo. La doctrina de Montesquieu conduce a una completa división teórica del Estado en tres personas, al quererse trasladar la doctrina a la realidad surgen dificultades prácticas y doctrinales. Las primeras obedecen a que las necesidades de la política no pueden ser dominadas por una fórmula abstracta. En Norteamérica era claro que los poderes pertenecían al pueblo, quien por medio de la constitución los atribuye a órganos específicos para que los representen.

Las Constituciones de los Estados, aún cuando hayan en principio admitido la tridivisión del poder, admiten un punto de unión en los mismos: el pueblo, lo cual significa el reconocimiento de la unidad del Estado. Cada órgano del Estado dentro de sus límites, representa el poder del Estado. Puede hablarse entonces de una división de competencias, pero no de una división de poderes. La literatura de derecho político, presenta una serie de ensayos confusos de clasificación, sin embargo, se mantiene con gran peso aquella que se para como direcciones fundamentales del poder del Estado las Funciones Legislativa, Ejecutiva (gobierno y administración) y Judicial, dejando de lado las diferencias relativas a la concepción de la naturaleza y modo de relacionarse éstas funciones, ninguna división ofrece una perfección lógica porque se trata de comprender la vida y no 


\section{REVISTA VIRTUAL VIA INVENIENDI ET IUDICANDI \\ "CAMINO DEL HALLAZGO Y DEL JUICIO"}

http://viei.usta.edu.co/ E-MAIL: revistainveniendi@usantotomas.edu.co

una materia muerta y todo lo vivo, aún cuando se dirija a la práctica, está a menudo privado de lógica, lo que se puede concluir es que es anticientífico querer agotar los poderes del Estado por la enumeración de sus contenidos. (JELLINEK 2000)

Una separación categórica funcional de las ramas del poder público, que corresponden al ejercicio del poder político del Estado, ejercidas por órganos instituidos para ese fin, no es factible en la realidad como en un esquema teórico, lo cual se debe a que al atribuir el ejercicio de una actividad exclusiva, da a las ramas del poder público independencia y autonomía, eliminando la cooperación como un útil instrumento de control, ya que trae consigo un equilibrio en el ejercicio del poder, la realización conjunta de actos mediando un grado de interdependencia y coordinación constituye un sistema de control básico en sí mismo (HUERTA 2001). La teoría de división del poder hoy no se refiere a la existencia de tres órganos, sino al ejercicio de tres funciones, la relación está establecida en la Constitución y se produce a raíz de vínculos que surgen a través de la asignación de funciones ejercitadas conjuntamente ya en forma simultánea o sucesiva. Esta cooperación sin duda evita la concentración de poder y cumple función de equilibrio y limitación al ejercicio del poder. El constitucionalismo constituye una muestra de la evolución de la civilización moderna y todo se ata a él, ya que provee al hombre de libertad y bienestar. En nuestro Estado Social, el constitucionalismo despliega uno de sus rasgos más importantes, el de control y 


\section{REVISTA VIRTUAL VIA INVENIENDI ET IUDICANDI \\ "CAMINO DEL HALLAZGO Y DEL JUICIO"}

http://viei.usta.edu.co/ E-MAIL: revistainveniendi@usantotomas.edu.co

equilibrio del poder, ya que en él se manifiesta una amplitud en el ejercicio del poder: por una parte la socialización del Estado y por otra la estatalización de la sociedad, ambas conectadas con la democracia pluralista. Nuestro Estado Constitucional, se basa en el pluralismo político y organizacional, lo cual es garantía de eficacia si se mira que se amplía el número de reguladores. La democracia está al servicio de los valores políticos, económicos y funcionales de la sociedad y es precisamente sobre el régimen democrático que se construye un verdadero y eficaz Estado Social. Sonia Patricia Cortés Zambrano

\section{EL CONTROL DEL PODER POLÍTICO Y LA CONSTITUCIÓN}

El control sobre los actos del gobierno ha tenido un desarrollo evolutivo en el tiempo, marcada en sus comienzos, anterior al Estado de derecho, en la medida en que los actos del gobierno correspondían a "actos del príncipe", discrecionales, absolutos y carentes de control. Al someterse el Estado al ordenamiento normativo, las actuaciones de quienes detentan el poder se limitan por el principio de legalidad, de igual manera, los actos del ejecutivo o del gobierno pueden ser susceptibles de control por otras instancias de poder. El Estado de Derecho moderno tiende al control no solo político si no jurídico de los actos de gobierno. El objeto de estudio en este apartado es el control al poder político, entendido éste desde su perspectiva jurídica, esto es a partir del análisis de las regulaciones 


\section{REVISTA VIRTUAL VIA INVENIENDI ET IUDICANDI \\ "CAMINO DEL HALLAZGO Y DEL JUICIO"}

http://viei.usta.edu.co/ E-MAIL: revistainveniendi@usantotomas.edu.co

jurídicas. Atendemos a la definición de poder como la posibilidad de imponen la propia voluntad sobre la conducta ajena (WEBBER 1964). El poder político se institucionaliza con la organización del Estado a través de normas jurídicas. El poder político se refiere concretamente a la posibilidad de ejercer la coacción, usando la fuerza legal, aplicando la ley, ya que el poder político se encuentra dispuesto en el ordenamiento jurídico.

El ejercicio del poder es necesario si se considera como la fuerza impulsadora en la toma de decisiones, la cual se ejerce con autoridad legítima. La autoridad es legítima en el poder político y la legitimidad corresponde a la condición de dominación o relación de subordinación. Es así como el poder político podría considerarse como la relación que surge entre quien detenta la autoridad y quienes están obligados legalmente a obedecer y que confirieron dicha autoridad al reconocerlo como legítimo, es por tanto la facultad reconocida por el orden jurídico para que determinados individuos actualicen sobre otros los mandatos contenidos en las normas jurídicas bajo amenazas de coacción, entendida ésta como la posibilidad fáctica de ejercer la fuerza física o moral sobre otro para que realice determinada conducta (HUERTA 2001). Por otra parte no se deja de lado esa tendencia natural de quien ostenta el poder de querer acrecentarlo incluso sobrepasando límites establecidos por la sociedad, la libertad y la dignidad humana. 


\section{REVISTA VIRTUAL VIA INVENIENDI ET IUDICANDI \\ "CAMINO DEL HALLAZGO Y DEL JUICIO" \\ http://viei.usta.edu.co/E-MAIL: revistainveniendi@usantotomas.edu.co}

Al generarse el abuso del poder o arbitrariedades, los gobernados pueden por la vía jurídica ponerles límite, en consecuencia para el buen funcionamiento de un Estado, es necesario el control al poder. A lo largo de la historia y posteriormente con desarrollo constitucional, se fueron organizando disposiciones encaminadas a limitar el ejercicio del poder y asegurar los derechos a los ciudadanos. No es, por cierto, la Constitución el único instrumento de control del poder sino que por su condición de Ley Suprema es el instrumento idóneo para modular sistemas de control. El orden jurídico dispone la regulación y ejercicio del poder político, que finalmente resulta de la capacidad de autodeterminación y autolimitación del pueblo. A partir de la Declaración de los Derechos del Hombre y del Ciudadano, se considera como una obligación que toda nueva Constitución contenga un capítulo destinado a derechos fundamentales y división de poderes, en la medida en que éstos constituyen los fundamentos del Estado de Derecho moderno, por tanto es en virtud de la distribución de competencias determinada en la Constitución, que las autoridades reciben facultades expresas para ejercer el poder público.

Es así como la Constitución le concede potestades al Estado como titular del poder y lo organiza jurídicamente, otorgándole diversas facultades, cuyos ejercicios deben cumplirse por los distintos órganos que lo conforman. La Constitución opera entonces, como organizadora del poder público y creadora de los órganos que lo ejercen otorgándoles competencias particulares. El poder del 


\section{REVISTA VIRTUAL VIA INVENIENDI ET IUDICANDI \\ "CAMINO DEL HALLAZGO Y DEL JUICIO"}

http://viei.usta.edu.co/E-MAIL: revistainveniendi@usantotomas.edu.co

estado es uno solo, pero es distribuido constitucionalmente en tres Ramas del Poder Público: Rama Ejecutiva: Encargada de ejecutar las normas y mediante la facultad reglamentaria se encarga de proporcionar el correcto acatamiento de las leyes y se encarga de la representación del país en el orden internacional; La Rama Legislativa: cuya principal función es elaborar las leyes de Estado, estableciendo la forma de relación entre los distintos órganos del Estado entre sí y las de éstos con los ciudadanos; La Rama Judicial: encargada de resolver las controversias de orden jurídico, vigila y mantiene la supremacía constitucional y ejerce como competencia la interpretación jurídica y la aplicación de la ley.

Es precisamente mediante esta distribución de competencias entre las ramas del poder público del Estado, contemplados en las disposiciones constitucionales, que se determina jurídicamente el poder político. Se establecen funciones y se crean los órganos con sus competencias y los procedimientos para cumplirlas, todo en coherencia con la Constitución y el orden jurídico. La Constitución establece limitaciones al poder a partir de los derechos fundamentales, principio de legalidad, equilibrio del poder y su división pro-competencias, etc., que tiene como propósito garantizar la vigencia de la soberanía nacional, instaurar modelos mínimos de conducta pública, obedeciendo al principio de legalidad. La Constitución por sí misma tiene dentro de sus funciones limitar el poder estatal, ordenando el proceso de formación de unidad política, mediante la limitación de 


\section{REVISTA VIRTUAL VIA INVENIENDI ET IUDICANDI \\ "CAMINO DEL HALLAZGO Y DEL JUICIO" \\ http://viei.usta.edu.co/ E-MAIL: revistainveniendi@usantotomas.edu.co}

atribuciones a los poderes estatales, regulación procesal de su ejercicio, y control del mismo (HESSE 1983).

En el Estado colombiano, que es un Estado constitucional, no podría desligarse la vinculación estricta entre el Control del Poder y el concepto de Constitución. Como ya se advirtió, ésta vinculación constituye el elemento político de la Constitución, ya que la división en tres ramas del poder público dispuesta en la Constitución, no significa la división del poder, sino la participación en el poder, es una concepción plural del ejercicio del poder (ARAGÓN 1999). El equilibrio perseguido por la Constitución, el del balance de los poderes. En el tiempo se puede verificar un camino progresivo hacia el fortalecimiento de los controles al poder, especialmente con el establecimiento de los tribunales constitucionales en 1920 (Austria), y en Europa a finales de la segunda guerra mundial, donde se erige la Constitución como una norma que supone el establecimiento y mantenimiento de las restricciones regularizadas, efectivas al poder. El sistema de restricciones efectivas al poder, se potencia a partir de la segunda posguerra mundial, organizada bajo la denominación de Estado de Derecho Democrático y Social, (República Federal Alemana), el interés del tema recae en el papel fundamental que en éste tipo de Estado desempeña el control. En el Estado Social se manifiesta la necesidad de Control, porque existe una gran extensión del poder, la socialización del estado y estatalización de la sociedad, requiere la efectividad en el control y las medidas que limiten en mayor o menor medida el poder, cuestión 


\section{REVISTA VIRTUAL VIA INVENIENDI ET IUDICANDI \\ "CAMINO DEL HALLAZGO Y DEL JUICIO"}

http://viei.usta.edu.co/ E-MAIL: revistainveniendi@usantotomas.edu.co

íntimamente relacionada con la concepción de democracia pluralista y tal como lo expresa (GARCÍA PELAYO 1977), es la democracia la que constituye la garantía de eficacia ya que multiplica el número de reguladores, y es la única llamada a servir a los valores políticos, económicos y funcionales de una sociedad desarrollada.

De ésta forma, la Constitución debe ser garantizadora de cooperación, responsabilidad y control en un Estado Social de Derecho, unificadora del poder, preservando y regulando su equilibrio. La Constitución comprende la fijación de los fines del poder y la regulación de su estructura, congruente con los fines pretendidos. La Constitución en su carácter normativo y vinculante, se funda en la limitación del Estado y no en su auto limitación, y en la democracia como expresión de la voluntad y soberanía del pueblo, al auto-determinarse constitucionalmente. El concepto de Constitución es un concepto finalista y tiene un fin específico que la distingue, la realización de la libertad, y la igualdad de esa libertad entre ciudadanos. Es ésta precisamente relación indisoluble la que caracteriza el Estado Constitucional de nuestros días, el Estado social y democrático. (ARAGON 1999). La democracia pluralista se hace realidad al margen de los controles, el Estado social no se concibe sin control, su existencia depende del Control. 


\section{REVISTA VIRTUAL VIA INVENIENDI ET IUDICANDI \\ "CAMINO DEL HALLAZGO Y DEL JUICIO"}

http://viei.usta.edu.co/ E-MAIL: revistainveniendi@usantotomas.edu.co

\section{El control al poder político}

En el contexto jurídico el control no se limita a supervisar actividades de otros o las propias, sino que establece métodos que evitan el ejercicio abusivo del poder, su función no es solamente comprobar que se acaten los límites, sino impedir acciones que vulneren normas o imponiendo sanciones a quienes extralimiten el rango de sus funciones, generando un abuso del poder. La razón de control en un Estado de derecho obedece a la oscuridad o ambigüedad y complejidad en el ordenamiento jurídico, que no permite que existan posiciones uniformes, y es precisamente el ordenamiento jurídico el que debe respetarse a la hora de ejercerse el poder, por tanto es tan imperioso buscar el equilibrio del poder a partir del control. El Control adoptado en el Estado Constitucional, es el vehículo a través del cual se hacen efectivas las limitaciones del poder (ARAGÓN 1999). E control del poder se manifiesta a través de múltiples formas, dependiendo de los objetos susceptibles de control. Control a las leyes, control a los actos del gobierno, control de la administración, control del poder legislativo, control del poder judicial entre otros. De la misma forma son varios los agentes llamados a ejercer control, tribunales de justicia, el Congreso en sus cámaras y comisiones, los congresistas, el gobierno, órganos de la administración, órganos de fiscalización o inspección, grupos de interés institucionalizados, opinión pública, ciudadanos etc. 


\section{REVISTA VIRTUAL VIA INVENIENDI ET IUDICANDI \\ "CAMINO DEL HALLAZGO Y DEL JUICIO"}

http://viei.usta.edu.co/ E-MAIL: revistainveniendi@usantotomas.edu.co

Los Conceptos de control son diversos, en virtud a la variabilidad de objetos que se pueden someter a él así como la pluralidad e sistemas de control que pueden ser establecidos, Aragón (1999), relaciona el control con el concepto de garantía, sin darles a los dos conceptos identidad epistemológica, sencillamente el control garantiza la limitación. En síntesis puede concluirse que el control es el conjunto de formalidades llamadas a garantizar, la validez, eficacia y vigencia de la limitación al ejercicio del poder. El Control se encuentra estructurado desde los comienzos del constitucionalismo, para asegurar la vigencia de a libertad y de los derechos del ser humano. El control de esta forma se analiza como un sistema que asegura el acatamiento del sistema jurídico. Loewenstein (1982, p 70), sustenta que el fin del control político al ejercicio del poder político, consiste en la posibilidad de exigir responsabilidad política, y existe cuando un detentador del poder da cuenta a otro del cumplimiento de la función que le han asignado, es entonces la responsabilidad el fundamento de los mecanismos de control. La responsabilidad se impone a quien se ha extralimitado en el ejercicio del poder, la sanción por tanto procede cuando no se ha podido evitar el abuso de poder, pero el control está llamado en principio a evitar que se comentan estos excesos que vulneren el equilibrio al que se encuentra llamado el ejercicio del poder político.

Las facultades que otorga el poder político, son vigiladas a través de procedimientos, supervisión, instituciones y además sanciones, por tanto la función de control no se reduce a la sanción, pues su primera misión es evitar el abuso de poder. 


\section{REVISTA VIRTUAL VIA INVENIENDI ET IUDICANDI \\ "CAMINO DEL HALLAZGO Y DEL JUICIO"}

http://viei.usta.edu.co/ E-MAIL: revistainveniendi@usantotomas.edu.co

El poder se manifiesta según Loewenstein (1982 P. 252), de dos formas, obligatorio y recíproco, por participar dos o más órganos en la realización de actos estatales en virtud de una norma jurídica, ya que éstos solo pueden llevar a cabo determinadas funciones; o control discrecional y unilateral si es un órgano respecto de otro y se considera facultativo por dejar al arbitrio de ése órgano la decisión de ejercer o no el control, e la medida en que el que despliega el ejercicio del poder se encuentra facultado para intervenir en la actividad del otro y frustrar sus acciones. El control al poder político tiene un factor discrecional, el cual radica en la oportunidad del ejercicio del acto de control más no en la forma de su ejecución. El control debe ejercerse en forma imparcial, no en aras de incrementar el poder de quien ejerce el control. La cooperación, la responsabilidad y el control que asegura la Constitución evitan el abuso del poder según Hesse (1983 P.20), por ello no es suficiente para, garantizar la eficacia del equilibrio y limites al poder, la regulación de un sistema de control, sino que es necesario establecer responsabilidades y sanciones para que en realidad las potestades no excedan el margen de su competencia. La estructura de un Estado constitucional, y por tanto de un gobierno constitucional, dispone que el poder sea repartido dividido entre varios cuyas voluntades confluyan a la formación de la voluntad estatal, por tanto y de acuerdo con Loewenstein (1982 p. 69), el mecanismo más eficaz de control es la designación formal de funciones, el control se ejerce mediante la cooperación entre órganos. Hesse (1983), señala, que el orden jurídico está llamado a garantizar la unidad estatal y la realización de sus funciones, "eliminando el abuso 


\section{REVISTA VIRTUAL VIA INVENIENDI ET IUDICANDI \\ "CAMINO DEL HALLAZGO Y DEL JUICIO"}

http://viei.usta.edu.co/ E-MAIL: revistainveniendi@usantotomas.edu.co

de competencias del poder", y se une al argumento de Aragón (1999), al señalar que "tal garantía no es solo cuestión de fijación de normas, sino, sobre todo, además, de actualización del orden jurídico".

El control político se enmarca en la condición subjetiva, en la medida en que la limitación es la consecuencia del choque entre dos voluntades, quien limita es a su vez quien controla, y el control se realiza por criterios basados en la oportunidad. Los agentes llamados a ejercer control político son cualificados, es decir deben tener condición política, no jurisdiccional (ARAGÓN 1999). Este control pretende fiscalizar y en ocasiones imponerse a otra voluntad, la relación que se da entre los agentes y objetos de control político no se basa en la independencia, pues no podría ser ejercida la fiscalización, se basa en la superioridad y el sometimiento en sentido estricto, abarcando el principio de jerarquía y el de supremacía. El control político es un control subjetivo, carente de neutralidad e imparcialidad. El Control político es un control institucionalizado, quienes están llamados a ejercerlo tienen una competencia jurídica preestablecida, es una potestad regulada cuyo ejercicio lo dispone el ordenamiento jurídico. De la misma manera solo pueden ejercer éste control agentes políticos institucionalizados, es así como no son los partidos los llamados a ejercer control político sino el Congreso, los congresistas y las bancadas. El ejercicio del control político recae sobre los órganos del poder y en éste sentido, puede ser controlado un acto político concreto, una actuación política general o incluso una norma. Se controla el órgano del que emana la decisión. 


\section{REVISTA VIRTUAL VIA INVENIENDI ET IUDICANDI \\ "CAMINO DEL HALLAZGO Y DEL JUICIO" \\ http://viei.usta.edu.co/ E-MAIL: revistainveniendi@usantotomas.edu.co}

El Control Político puede ser previo o sucesivo de actividades a realizar o ya realizadas, sus criterios de valoración varían en virtud a su subjetividad, por tanto estaríamos ante el choque de dos voluntades, el parámetro de control lo establece la libre voluntad de quien controla. La valoración se efectúa con libertad absoluta de discernimiento lo cual da paso a la libertad de conformación del parámetro, es decir el carácter puramente político o de oportunidad, en la moción de censura, por ejemplo, la cuestión de confianza, las interpelaciones y sin lugar a dudas en las elecciones. Cuando se ejerce control se acude necesariamente a la Constitución o la ley para revisar una conducta o acto, y su interpretación es libre, ya que es una interpretación política no jurídica. Es el caso del control del Congreso sobre un decreto ley, puede rechazarlo por inadecuado políticamente inoportuno, allí el canon es netamente subjetivo, pero puede rechazarlo por inconstitucional, pero en este caso la decisión de rechazo es política en la medida en que es adoptada por votación, la interpretación de constitucionalidad es la misma que la adoptada al momento de redactar una ley. Siempre se tratará de una decisión política basada en razones políticas, lo cual constituye la condición sustancial del control político. El resultado del control, no configura el control político en sí mismo, el solo hecho de someterse a juicio un acto o un proyecto ya implica resultado, la demostración de inspección y juicio del poder, su crítica, fiscalización y valoración pública e institucionalizada por sí misma ya es control. También puede generarse una decisión de censura del objeto controlado políticamente, pero su carácter subjetivo, excluye que necesariamente el juicio 


\section{REVISTA VIRTUAL VIA INVENIENDI ET IUDICANDI \\ "CAMINO DEL HALLAZGO Y DEL JUICIO"}

http://viei.usta.edu.co/ E-MAIL: revistainveniendi@usantotomas.edu.co

negativo conlleve automáticamente la anulación del objeto, o la remoción del titular de la acción, lo cual no excluye la posibilidad de que existan características sancionatorias en sentido estricto cuando el ordenamiento jurídico así lo establezca. El control político no tiene carácter sancionatorio per. se, solo de manera excepcional.

\section{Tipología del control político}

Se origina en virtud a la diversidad de objetos que pueden ser susceptibles de control: Normas Jurídicas, actos de gobierno del Poder Ejecutivo, de la Administración Pública, del Poder Legislativo, o del Poder Judicial, o debido a la variedad de sujetos que realizan la función de control, específicamente la forma en la que se relacionan los órganos y los individuos y finalmente de acuerdo a la temporalidad, que tiene que ver con el hecho de valorar una actuación previa a que surta efectos o posterior a su ejecución cuando ya ha generado efectos, y si se han generado perjuicios ya corresponde al interesado demandar la decisión. Loewenstein (1982 p. 232), reparte la función de control entre quienes detentan el poder por orden constitucional, el gobierno, el congreso en el caso colombiano, los tribunales y el electorado. Afirma que el control puede ser aplicado en forma vertical, entre los poderes establecidos constitucionalmente y la sociedad, y horizontal, el cual opera dentro de la organización del Estado: intraorgánicos, ínter orgánicos, los cuales operan entre los órganos estatales en forma recíproca y a 


\section{REVISTA VIRTUAL VIA INVENIENDI ET IUDICANDI \\ "CAMINO DEL HALLAZGO Y DEL JUICIO" \\ http://viei.usta.edu.co/ E-MAIL: revistainveniendi@usantotomas.edu.co}

través de la cooperación, los cuales son los que nos ocupan en ésta obra, y que evitan la concentración de poderes y facultades o la obstrucción en las actividades propias de cada rama del poder público, lo que permite concluir que de la asignación específica de funciones se desprende una importante forma de control. Una Clasificación distinta presenta Jellinek (2000 p. 91 Y 92), quien establece en primera instancia la existencia de controles generales y difusos, que corresponderían en principio a las limitaciones no institucionalizadas, no regulados en el ordenamiento jurídico y constitucional, no controlables por ejemplo, la opinión pública; y los controles institucionalizados jurídicos o políticos, los primeros amparados en la preexistencia de normas y los segundos de ejercicio voluntario y subjetivo.

\section{Controles recíprocos entre órganos del poder}

En el Estado Constitucional Colombiano, en donde se establece el sistema político democrático y presidencial, se presentan controles entre la Rama Ejecutiva a la Rama Legislativa, de la Rama Legislativa al Ejecutivo, de la Rama Judicial hacia el Legislativo y el Ejecutivo, y hacia los tres poderes por parte del electorado. Estando de acuerdo a los postulados del Loewenstein, en el sentido del control político como control al gobierno o quienes ejercen el poder a través de la determinación de funciones damos paso al análisis de las relaciones de control político entre las ramas del poder público en Colombia, no sin revisar las los 


\section{REVISTA VIRTUAL VIA INVENIENDI ET IUDICANDI \\ "CAMINO DEL HALLAZGO Y DEL JUICIO"}

http://viei.usta.edu.co/ E-MAIL: revistainveniendi@usantotomas.edu.co

poderes de cada Rama enfocados en sus funciones y su organización actual, en el marco del sistema presidencialista colombiano, para aterrizar propiamente en el control legislativo, entre Rama Ejecutiva, Rama Legislativa y Corte Constitucional. La lógica constitucionalista, hizo patente la necesidad de establecer y mejorar mecanismos de control político. Para el caso de estudio, se analizan los mecanismos o instrumentos de control del Poder Legislativo, que le permitieran dentro del sistema presidencial, cumplir con el control al Poder Ejecutivo y viceversa, y por otra parte, el control que ejerce la Corte Constitucional en materia de producción legislativa.

Para concluir, existen criterios para tipificar y cualificar el control al ejercicio del poder político: Según el modo de ejercicio, el cual puede ser político (discrecional), Jurídico (necesario), Administrativo (Jurídico y discrecional). Según el objeto controlado que pueden ser actos, leyes o sujetos. Según el órgano que ejerce el control, puede ser control del ejecutivo, control del legislativo, control judicial o control del electorado, según su taxatividad generales o difusos, o institucionalizados jurídicos o políticos. Según sus efectos pueden ser preventivos, de reparación, de anulación, según la temporalidad, pueden ser previos o posteriores, según su realización puede ser conjunta (Sucesiva), o independiente, según el ámbito de acción, Vertical u Horizontal (intraorgánicos o interorgánicos). 


\section{REVISTA VIRTUAL VIA INVENIENDI ET IUDICANDI \\ "CAMINO DEL HALLAZGO Y DEL JUICIO"}

http://viei.usta.edu.co/ E-MAIL: revistainveniendi@usantotomas.edu.co

\section{Principio de División de Funciones fundamento del control político:}

Como se ha mencionado ya, si bien de Montesquieu no se aplica en la actualidad, si sirvió como fundamento para establecer la estructura funcional del Estado moderno. Subraya la importancia de constituir los diferentes campos de acción del Estado, a través de los cuales se materializa el poder político. La estructura parte de la separación de de las autoridades de acuerdo con las funciones que van a realzar delimitando el ámbito de su competencia y en segundo lugar estableciendo relaciones de cooperación y control entre los poderes (HUERTA 2001). Es claro entonces que la división funcional entre las ramas del poder, independientes entre sí, cuyas facultades sean diferentes y complementarias, logran el funcionamiento y la continuidad del Estado, evitando el abuso y la concentración del poder. Schmitt (p. 186 1982) afirma que la clásica división de poderes constituye un principio orgánico que asegura la moderación en la acción y control de de los órganos del Estado, y de allí se deriva el equilibrio. Por tanto las autoridades y sus competencias separadas, establecen relaciones de influencia y contrapeso recíproco, al margen de la incompatibilidad de funciones, evitando la concentración de poder. En el mismo sentido Aragón (1999 p. 38), señala que concurren la cooperación funcional, controles mutuos, frenos y contrapesos, con la mezcla de división de poderes y una forma mixta de gobierno, estructurada en la Constitución y Loewestein (1982 p. 55) al presentar su teoría de separación 


\section{REVISTA VIRTUAL VIA INVENIENDI ET IUDICANDI \\ "CAMINO DEL HALLAZGO Y DEL JUICIO"}

http://viei.usta.edu.co/ E-MAIL: revistainveniendi@usantotomas.edu.co

funcional, señala que la distribución de poderes constituye en sí un control recíproco, en virtud de la constitución, y que los casos de cooperación deben ser prescritos por la constitución.

Se concluye que la finalidad de ésta relación entre las ramas del poder se enmarca en el equilibrio y la independencia, logrando un balance que impida el ejercicio extralimitado de las facultades en detrimento de las potestades de otro o de los otros. El control ínter orgánico se basa en la posibilidad de ejercer influencia por un detentador del poder sobre otro, las actividades de poder se ejecutan por cuatro actores: el Electorado, el Congreso, el Gobierno y los Tribunales. El Electorado legitima los otros tres, Por tanto se prevén básicamente trs categorías de control inter-orgánico:

1. Del Congreso frente al Ejecutivo

2. el Gobierno frente al Congreso

3. Los controles de los Tribunales frente al Congreso y al Gobierno (control de legalidad y de constitucionalidad principalmente) 


\section{PRESIDENCIALISMO: RELACIÓN ENTRE LEGITIMIDAD DEL PODER Y EQUILIBRIO DE PODER}

La doctrina constitucional afirma que todo Estado de Derecho, se fundamenta en la dignidad de la persona que se realiza en los derechos individuales y colectivos y en la separación y equilibrio de los poderes, ambos establecidos en la Constitución. De éstos principios, surge la exigencia de control al poder político, asegurando el correcto ejercicio tanto del poder en la libertad, como los derechos en la solidaridad, frente a los inevitables abusos a que son propensos, tanto la actuación del poder político como la de los derechos individuales y sociales. La Constitución en el Estado Social de Derecho, funciona como ley de limitaciones y garantías, y en el caso del poder político, la constitución dispone mecanismos de control sobre el poder.

Los presupuestos para el control se basan particularmente en. La independencia del órgano controlante respecto del controlado, el deber de precisar el ámbito de lo controlado, y el derecho a la información y publicidad de los actos. (HARO 2002). Aunque existe mecanismos de control no todos son eficaces, pero se resaltan como control mecanismos al poder ejecutivo: el sufragio popular, que no es otra cosa que la aprobación de los actos del gobierno por parte de la ciudadanía, el electorado hace una conciencia democrática racional, demostrando claramente un 


\section{REVISTA VIRTUAL VIA INVENIENDI ET IUDICANDI \\ "CAMINO DEL HALLAZGO Y DEL JUICIO"}

http://viei.usta.edu.co/ E-MAIL: revistainveniendi@usantotomas.edu.co

control político. Aquí la responsabilidad es considerada como el objeto central de los esquemas de representación, lo cual asegura una rendición de cuentas. El Pluripartidismo, en la medida en que en los sistemas de partidos únicos o hegemónicos, no existe el sustento político para la discrepancia y al crítica, por tanto el pluripartidismo, genera oposición y crítica al gobierno lo cual fortalece el control político.

La Oposición en el Congreso, no siempre efectiva y vigorosa, con medios eficaces para realizar control sobre las actividades gubernamentales, El Control de legalidad y Constitucionalidad, defensoría del pueblo, que defiende y protege los derechos humanos y demás derechos y garantías constitucionales. Un repaso de la historia del presidencialismo colombiano arroja como resultado dos centros de crisis: la situación de los partidos tradicionales: burocratización y crisis ideológica, carencia de alternativas de programas en el poder, y que suponen afección a la actividad del Congreso y los nuevos rumbos del orden económico que generaron prácticas monopolistas, separando de la realidad la disposición constitucional de la libre empresa.

Se perciben entonces las siguientes tendencias que deforman el Estado democrático en el sistema presidencial colombiano: 


\section{REVISTA VIRTUAL VIA INVENIENDI ET IUDICANDI \\ "CAMINO DEL HALLAZGO Y DEL JUICIO"}

http://viei.usta.edu.co/ E-MAIL: revistainveniendi@usantotomas.edu.co

- Excesivo poder presidencial: Por las facultades económicas y las delegaciones que le permiten absorber facultades de los otros poderes.

- Decadencia del Congreso: al dejar de ejercer la tarea fiscalizadora del ejecutivo y la expectativa de sus integrantes frente a su aspiración de ingresar al gobierno central o a las gobernaciones.

- Estado de sitio permanente: La militarización de la justicia es la mentalidad de los partidos tradicionales, a los cuales no les preocupa la sustitución de los poderes normales del estado por otros de tipo excepcional.

- La pobreza en aumento: marginamiento grave de una gran parte de la población colombiana, aumentando la diferencia entre las clases sociales. Colombia se ancla en el sistema presidencial, la hipertrofia de facultades que rodean al primer mandatario, hacen de él, el único poder efectivo del Estado. El poder legislativo ha perdido paulatinamente su importancia como foro de grandes debates ideológicos. Revaluado queda el concepto de separación rígida de poderes, ya que es incuestionable, que todos están llamados a cumplir funciones unitarias dependientes. Dentro de un Estado democrático, no cabe suponer un presidente desligado del cuerpo legislativo, para dictar los decretos o reglamentos de tipo económico o social. (VASQUEZ 1979) 


\section{REVISTA VIRTUAL VIA INVENIENDI ET IUDICANDI \\ "CAMINO DEL HALLAZGO Y DEL JUICIO"}

http://viei.usta.edu.co/ E-MAIL: revistainveniendi@usantotomas.edu.co

En Colombia, el exceso de poder presidencial, abre la puesta al poder autocrático, el juego de balanza entre ejecutivo y legislativo se encuentra descompensado por definición en un sistema presidencial a favor del primero, la función de control por parte del Congreso es limitada y esta limitación al control político se acentuó y asentó en el Congreso desde los pactos del Frente Nacional que eliminaron la oposición. El resultado es la decadencia de la rama legislativa y el aumento desmedido de poder en cabeza del ejecutivo, para planear y ejecutar políticas económicas y sociales de ésta forma se verifica la nueva dimensión del poder en el orden público económico.

El régimen presidencial absorbe la totalidad de las energías del Estado, concentra en forma excesiva en el gobierno decisiones fundamentales y hace un tanto inútiles las instituciones complementarias o descentralizadas, pues todas ellas dependen de aquel. El tema que queda pendiente se centra en la recuperación democrática del Congreso, los partidos, y la institución del orden económico y social como uno de los componentes del Estado, con una definición clara de su existencia, y de los criterios de Justicia Social y de participación. 


\section{REVISTA VIRTUAL VIA INVENIENDI ET IUDICANDI \\ "CAMINO DEL HALLAZGO Y DEL JUICIO"}

http://viei.usta.edu.co/ E-MAIL: revistainveniendi@usantotomas.edu.co

\section{Régimen presidencial en la Constitución Política de Colombia de 1991}

En el año de 1991, una Asamblea Nacional Constituyente, redacta y ratifica una nueva Constitución para Colombia, la cual pretendía remediar el desequilibrio latente entre un presidente excesivamente poderoso y un Congreso que parecía incapaz de llevar a cabo las agendas políticas que respaldan los partidos que lo integran. Dentro de los elementos del Régimen Presidencial a punto de lo dispuesto en la Constitución de 1991 tenemos: la autoridad del presidente, el poder ejecutivo se encuentra centrado en cabeza del presidente cuya legitimidad radica en su carácter representativo, los ministros no forman un gobierno, es decir un órgano con tareas y responsabilidades propias; relación independiente entre gobierno y congreso, la rama ejecutiva, el presidente y sus ministros dispone del poder ejecutivo y la rama legislativa, es decir el Congreso dispone del poder legislativo, cada uno por la duración de sus mandatos, sistema de frenos y contrapesos: cada órgano tiene la posibilidad de condicionar y controlar a los otros en el ejercicio de sus respectivas funciones, del sistema de pesos y contrapesos, se deduce que la orientación política corresponde a un acuerdo entre el Congreso y el Presidente, previo proceso de concertación y negociación entre los dos poderes. (ESTRADA 2003). 


\section{REVISTA VIRTUAL VIA INVENIENDI ET IUDICANDI \\ "CAMINO DEL HALLAZGO Y DEL JUICIO"}

http://viei.usta.edu.co/ E-MAIL: revistainveniendi@usantotomas.edu.co

El Estado como poder organizado se constituye por un número de instituciones particulares que desempeñan determinadas tareas políticas, en el caso del Gobierno- Ejecutivo se entiende que es el heredero directo del poder soberano, limitado por la constitución y la Ley. El papel de predominio del ejecutivo gobierno dentro del sistema estatal, es el que determina que hacia el confluyan todos los esfuerzos de las clases y grupos sociales para obtener su control e influencia. Control mediante los Partidos Políticos y los Grupos de Presión. (ECHEVERRI 2002).

\section{Rama Ejecutiva en la Constitución de 1991}

Las modificaciones del Poder Ejecutivo, evidenciadas en la constitución de 1991, comprende aspectos formales y de fondo, los cuales van desde los requisitos para ser presidente, su forma de elección, sus atribuciones, en especial las que tiene que ver con los Estados de Excepción, la restauración de la figura del Vicepresidente, la relación con la fuerza pública, las relaciones internacionales y la Función Administrativa. (NARANJO 1992) La Rama Ejecutiva tiene como fin, ejecutar la ley, hacerla efectiva proveyendo a la esfera administrativa, la facultad de expedir reglamentos los cuales no deben contravenir la ley que reglamentan ni la Constitución. Tiene igualmente facultades legislativas, como la iniciativa de ley, su promulgación y la facultad reglamentaria, la cual se considera una verdadera excepción al principio de separación funcional, dado que el Ejecutivo realmente 


\section{REVISTA VIRTUAL VIA INVENIENDI ET IUDICANDI \\ "CAMINO DEL HALLAZGO Y DEL JUICIO"}

http://viei.usta.edu.co/E-MAIL: revistainveniendi@usantotomas.edu.co

legisla al expedir un reglamento. Se le atribuyen igualmente facultades administrativas como realizar nombramientos, dirigir relaciones diplomáticas, celebrar tratados, y ejercer funciones relacionadas con la seguridad del país. De poder ejecutivo depende la organización administrativa, la gestión de trámites y la organización de los servicios públicos, además de la representación del Estado en el exterior. Dentro de sus funciones está la de controlar el poder legislativo, evitando que supere su esfera de competencias.

La Constitución de 1991 en su artículo 115 mantiene una redacción similar al de la Constitución de 1886, pero introduce adiciones al concepto de gobierno. El título VII de la Constitución dedica un capítulo al Gobierno, y contiene los artículos relativos a las funciones del gobierno en relación con la rama legislativa y judicial, entendiendo gobierno como una estructura política que conlleva a un manejo del poder político encaminado hacia los efectos sociales del nivel general. (Sentencia C-195 de 1994).

\section{Facultades del Ejecutivo en materia de control}

El poder ejecutivo tiene como finalidad principal la ejecución de la ley, partir de ello provee a la administración, medios adecuados para ello, dentro de éstos se encuentra la potestad de expedir reglamentos, en el marco de la ley que reglamentan. Tiene igualmente y como ya se especificó facultades relacionadas 


\section{REVISTA VIRTUAL VIA INVENIENDI ET IUDICANDI \\ "CAMINO DEL HALLAZGO Y DEL JUICIO"}

http://viei.usta.edu.co/ E-MAIL: revistainveniendi@usantotomas.edu.co

con el procedimiento legislativo, así la iniciativa legislativa, y la facultad reglamentaria constituye una real excepción al principio de separación de poderes, dado que se le faculta constitucionalmente al ejecutivo para legislar. También ya señaladas sus facultades administrativas y las relativas a la justicia y la seguridad del país.

La rama ejecutiva del poder público, despliega funciones a fin de equilibrar el poder del legislativo y controlar sus actos, buscando que éste no se convierta en un órgano superior, que salvaguardado en su legitimidad, emita leyes que lo faculten por fuera de la Constitución y de su esfera de competencias.

\section{Controles del Gobierno al Congreso}

Basados en la teoría de controles horizontales presentada por Loewestein (1982), analizaremos el desarrollo en el caso colombiano: Injerencia del Gobierno en el proceso legislativo: siendo Colombia una democracia constitucional, la intensidad de la participación gubernamental, depende del tipo de gobierno vigente, el ejecutivo puede negociar con las bancadas las políticas que pretende adelantar, puede solicitar el trámite de urgencia para cualquier proyecto de ley, lo cual genera que tenga prelación sobre cualquier otro asunto, por otra parte cualquier

proyecto de ley negado en primer debate puede ser considerado por la respectiva cámara a solicitud del gobierno, lo anterior según lo dispuesto en los artículos 159 


\section{REVISTA VIRTUAL VIA INVENIENDI ET IUDICANDI \\ "CAMINO DEL HALLAZGO Y DEL JUICIO"}

http://viei.usta.edu.co/ E-MAIL: revistainveniendi@usantotomas.edu.co

y 163 de la Constitución Colombiana Injerencia sobre la ley promulgada: el control inter-orgánico del gobierno sobre las leyes adoptadas es máximo en los sistemas presidenciales, si se tiene en cuenta el principio constitucional de coordinación entre las actividades o funciones de las distintas ramas del poder público. La sanción de la ley, que permite evidenciar su aceptación por parte del gobierno, tiene carácter definitivo, de la misma forma el veto presidencial en Colombia, develado en la posibilidad que tiene el Gobierno de objetar las leyes, devolviéndolas a la cámara de origen, demuestran la injerencia del gobierno en la producción legislativa, artículos 157, 165 y 166 de la Constitución Política de 1991.

Facultades legislativas del Gobierno: La Constitución de 1991, como ya se mencionó algunos renglones atrás, otorga al presidente, la autoridad exclusiva para iniciar legislación en ciertas áreas de políticas (leyes sobre estructuras de los ministerios del ejecutivo, leyes que establezcan salarios para los funcionarios públicos y normas generales para la regulación del cambio, el comercio exterior, la deuda nacional y las tarifas), y sobre temas específicos ya enumerados, a su vez, posee la potestad reglamentaria (artículo 189 C.P.), la cual ejerce mediante la expedición de Decretos, Resoluciones, y Ordenes necesarias para el cumplimiento de las leyes, y éste en sí, constituye el atributo sin duda más importante, cuya finalidad es dar cumplida ejecución a las leyes, la cual es por excelencia la potestad administrativa del Presidente. Lo anterior corresponde al argumento de Loewentein (1982 p. 274), cuando afirma que la transformación del Estado en 


\section{REVISTA VIRTUAL VIA INVENIENDI ET IUDICANDI \\ "CAMINO DEL HALLAZGO Y DEL JUICIO"}

http://viei.usta.edu.co/ E-MAIL: revistainveniendi@usantotomas.edu.co

Estado Constitucional y Administrativo, conduce a un cambio importante en la dinámica del poder, las constantes intervenciones gubernamentales en la vida social y económica, hacen de la órbita de vigilancia y regulación estatal un campo más denso, destacando la ampliación en la interacción entre el ciudadano y la administración.

En Colombia, el ordenamiento jurídico ha estructurado un régimen presidencial, por tanto, la jefatura de Estado y de gobierno no se escinden y son asumidas por una persona titular del poder ejecutivo: el Presidente de la República, quien es electo popularmente y designa al gabinete ministerial. El Presidente no puede ser miembro de dos poderes simultáneamente, ni disolver el Congreso, ni éste a su vez puede remover al presidente mediante la Moción de Censura como ocurre en los sistemas parlamentarios. Esto produce la independencia de los órganos constitucionales respecto del poder legislativo. El sistema presidencial colombiano se fundamenta en la estructura de separación de los órganos constituidos y a la distribución de funciones y sus relaciones. Es una forma de organización dentro de un régimen republicano. La Constitución de 1886 se caracterizaba por un Ejecutivo fuerte, independiente en la realización de sus funciones, y con facultades importantes, que ciertamente potenciaban su poder frente a las demás ramas del poder público. 


\section{REVISTA VIRTUAL VIA INVENIENDI ET IUDICANDI \\ "CAMINO DEL HALLAZGO Y DEL JUICIO"}

http://viei.usta.edu.co/ E-MAIL: revistainveniendi@usantotomas.edu.co

La Constitución de 1991, quiso limitar estos poderes y fortalecer los procesos de control por parte del legislativo, para garantizar un ejercicio del poder equilibrado. Trajo consigo algunos procedimientos propios del sistema parlamentario, algunos de los cuales sin eficacia como ya se revisará, y otros que aunque existan no alteran el régimen presidencial establecido en la propia Constitución, aunque eso sí llamados a ajustar el principio de separación de poderes y enmarcarlo en el juego del equilibrio y la colaboración armónica funcional entre las ramas del poder público. Dentro de los controles que el Ejecutivo ejerce sobre el Legislativo, se encuentran: la posibilidad de influir en el proceso legislativo, sobre la ley promulgada y las facultades legislativas del Gobierno.

A su vez Loewestein (1982 p.255,259), Considera, que para que se de el funcionamiento del control del parlamento frente al gobierno, es preciso que se elimine la influencia de éste en la elección de los miembros del poder legislativo, lo mismo que el control de éste sobre las sesiones del Congreso. También debe ser eliminada toda influencia sobre el funcionamiento de las cámaras, así como toda posibilidad de que el gobierno ejerza presión en los miembros del parlamento, ataca el nepotismo o favoritismo o patronaje, y plantea la incompatibilidad de los cargos parlamentarios con los profesionales. Resumiendo, el Presidente de la República según el artículo 167 de la Constitución Política de 1991, tiene la facultad de objetar total o parcialmente un proyecto de ley, el cual vuelve a las Cámaras para un segundo debate. Por otra parte el Presidente, también por 


\section{REVISTA VIRTUAL VIA INVENIENDI ET IUDICANDI \\ "CAMINO DEL HALLAZGO Y DEL JUICIO"}

http://viei.usta.edu.co/ E-MAIL: revistainveniendi@usantotomas.edu.co

disposición constitucional puede solicitar trámite de urgencia para cualquier proyecto de ley, artículo 163, y la facultad de poder convocar al Congreso a sesiones extraordinarias, facultades que en forma clara evidencian potestad del ejecutivo ante el legislativo, si se revisa su gran poder de negociación.

A manera de Conclusión, es claro que las opiniones se dividen entre quienes afirman que tras la Constitución de 1991, se debilitó el presidencialismo colombiano, argumentando razones como la descentralización política, administrativa y fiscal, las limitaciones a los Estados de Excepción, la independencia del Banco de la República, mientras que otros señalan que en Colombia existe una presidencia fortalecida, si se revisan las potestades del Presidente como Jefe de Estado y Jefe de Gobierno, comandante de las fuerzas armadas, y como suprema autoridad administrativa, además de su influencia en el sector privado de la economía y además, la posibilidad que le asiste al primer mandatario de designar a sus funcionarios sin autorización del Congreso y sin ningún contrapeso en sus decisiones de política exterior, poder que se aumenta significativamente específicamente en su poder de nominación con la reelección presidencial, (como en el caso de la elección de los miembros de la Junta directiva del Banco de la República) y para otros existe un poder formal normativo distinto del poder real del Presidente. Se pone de manifiesto la necesidad de esclarecer si existe o no concentración de poder, gobernabilidad negociada, pérdida de control territorial, fractura del orden social, descomposición política, 


\section{REVISTA VIRTUAL VIA INVENIENDI ET IUDICANDI \\ "CAMINO DEL HALLAZGO Y DEL JUICIO"}

http://viei.usta.edu.co/E-MAIL: revistainveniendi@usantotomas.edu.co

desinstitucionalización, enfrentamiento entre Gobierno y Congreso, las elecciones vistas como eje de la actividad política, división y falta de identidad ideológica en el marco político, inexistencia de garantías para la oposición, debilidad institucional de los partidos políticos y de las funciones del legislativo, que a su vez generan debilidad en el control político al Ejecutivo y en consecuencia la verificación de la concentración del poder en su cabeza. Para ello es necesario verificar la estructura, evolución y función de la Rama Legislativa de Poder Público para confirmar la tesis de debilidad institucional.

El presidencialismo que impera en Colombia, le otorga al presidente en ejercicio ciertas ventajas, el Presidente puede controlar al Congreso, la nómina oficial y el presupuesto son las herramientas usadas para alcanzar ese propósito. El primer mandatario puede convertir la empresa privada en su principal aliado, de ésta manera influye en la marcha de los negocios, los medios de comunicación generalmente están al margen de emitir críticas, por su parte los entes territoriales dependen económicamente en la práctica del Presidente, pues no existe posibilidad de ejecución de obras de gran envergadura sin el apoyo del gobierno nacional, y sus nombramientos no necesitan de la ratificación del congreso. Por su parte el manejo estratégico de los recursos políticos que pueden utilizarse para influir sobre la conducta de las personas, son la fuerza física, el armamento, el dinero, los bienes y servicios, recursos productivos ingresos, honor, respeto, carisma, prestigio, educación, comunicación, votos, etc. (DAHL 1999 p. 199) 


\section{REVISTA VIRTUAL VIA INVENIENDI ET IUDICANDI \\ "CAMINO DEL HALLAZGO Y DEL JUICIO"}

http://viei.usta.edu.co/ E-MAIL: revistainveniendi@usantotomas.edu.co

Atendiendo a lo anterior podría decirse que en efecto el gobierno puede favorecerse, al tener en su poder recursos políticos para convencer al electorado, el desarrollo de su buen gobierno que genere beneficio para la mayoría constituye un factor determinante al momento de aspirar a una reelección, y algunos califican esto como una rendición de cuentas, premiado con una continuidad en el poder otorgada por el electorado. ¿Se rompe aquí el principio de la competitividad?, yo creería que no sin embargo no estoy de acuerdo a dos periodos seguidos de reelección, pues en ese caso si se afecta el principio democrático sin duda.

\section{La Oposición y el Control}

Se analiza en este apartado, el control del Congreso en el Congreso (ARAGÓN 2002), el cual puede incluso verificarse al interior de la actividad de las cámaras, en la manifestación de sus decisiones, decisiones de la mayoría, pero que son asistidas a su vez con la intervención de los grupos minoritarios o de oposición, de la misma forma se configura la oposición como fiscalizadora de los actos de gobierno, y en este principio se centra esa importante atribución de derechos de control que ostenta la oposición. 


\section{REVISTA VIRTUAL VIA INVENIENDI ET IUDICANDI \\ "CAMINO DEL HALLAZGO Y DEL JUICIO"}

http://viei.usta.edu.co/ E-MAIL: revistainveniendi@usantotomas.edu.co

\section{Facultades del Congreso en materia de control}

Una gran función del Congreso de la República consiste en el control político ejercido sobre el gobierno. Para llevarla a cabo cuenta con tres herramientas fundamentales, las preguntas formuladas a los ministros y a los altos funcionarios del gobierno, el estudio de los balances anuales, y la moción de censura. En el primer caso los congresistas solicitan a los ministros respondan a las preguntas realizadas en sesiones plenarias, las preguntas son enviadas al ministro y éste debe responderla dentro de los siguientes 5 días de su recepción, otros funcionarios pueden responder ante el Congreso en las sesiones desarrolladas en cada comisión (GECHEM 2005).

En el segundo caso el Procurador General de la Nación, el Defensor del Pueblo, el Contralor General de la República, y el Banco de la República, anualmente deben presentar ante el Congreso un informe sobre el trabajo realizado y el cumplimiento de sus funciones, así como está obligado el gobierno en caso de Estados de Excepción o conmoción interior y de guerra exterior, explicar las causas de su declaratoria. De igual manera, el Gobierno se encuentra obligado a pedir el visto bueno al Congreso cundo se trata de realizar privatizaciones e indultos concedidos respecto de delitos políticos. 


\section{CONTROL POLÍTICO CONGRESO - GOBIERNO EN COLOMBIA Moción de Censura en Colombia.}

Introducida por la Constitución de 1991 y desarrollada por el artículo 29 de la ley $5^{\text {a }}$ de 1992. Cabe resaltar que la responsabilidad política en el sistema presidencial colombiano se lleva a cabo a través de citaciones y debates que promueven las cámaras a los ministros o altos funcionarios del gobierno, pero con la salvedad de que no los pueden destituir; y mucho menos no pueden ni destituir ni hacer renunciar al presidente de la República quien ha sido elegido para un periodo fijo; es conocido en su forma más amplia como la figura de frenos y contrapesos (checks and balances), no existe derecho de disolución del parlamento o del gobierno bajo ninguna circunstancia o pretexto puede disolver el parlamento pues ello conllevaría a un golpe de Estado y la constitución de un régimen de facto. (NARANJO 2006).

El artículo 135 de la C.P modificado por el acto legislativo 01 de 2003 en sus artículos 1,2 y 7 que prevé la figura de moción de censura como facultad de control político que se le ha otorgado al Congreso de Colombia en cada una de sus cámaras ya que como se ha explicado a lo largo de este texto es el tema central a desarrollar por lo tanto será motivo de discusión más adelante. 


\section{REVISTA VIRTUAL VIA INVENIENDI ET IUDICANDI \\ "CAMINO DEL HALLAZGO Y DEL JUICIO"}

http://viei.usta.edu.co/ E-MAIL: revistainveniendi@usantotomas.edu.co

\section{El Juicio Político en Colombia}

Establecido en el artículo 174 de la C.P en el cual establece que "corresponde al senado conocer de las acusaciones que formule la cámara de representantes contra el Presidente de la República o quien haga sus veces...", aunque este hubiera cesado en el ejercicio de su cargo. Conocerá el senado "por hechos $u$ omisiones ocurridos en el desempeño de los mismos". Artículo 175 de la C.P el senado deberá tener en cuenta al momento del juicio el delito que presuntamente se haya cometido. Así en el numeral 2 se indica que "si la acusación se refiere a delitos cometidos en el ejercicio de funciones o a indignidad por mala conducta, el senado no podrá imponer otra pena que la destitución del empleo o privación temporal o pérdida absoluta de los derechos políticos...". De igual manera el numeral 3 prevé que "si la acusación se refiere a delitos comunes, el senado se limitará a declarar si hay o no lugar a seguimiento de causa y, en caso afirmativo pondrá al acusado a disposición de la corte suprema".

Artículo 178 numeral 3 de la C.P indica que dentro de las atribuciones especiales que detenta la cámara de representantes se encuentra la de "acusar ante el senado, cuando hubiere causas constitucionales, al Presidente de la República o quien haga sus veces..."; es decir que la etapa inicial de este juicio se realiza en la cámara de representantes que posteriormente conocerá el senado y el cual tiene la facultad de adelantar el juicio. 


\section{REVISTA VIRTUAL VIA INVENIENDI ET IUDICANDI \\ "CAMINO DEL HALLAZGO Y DEL JUICIO"}

http://viei.usta.edu.co/ E-MAIL: revistainveniendi@usantotomas.edu.co

\section{Control Político a los Estados de Excepción}

El artículo 212 de la C.P una vez el Presidente de la República con la firma de todos sus ministros declare el Estado de Guerra exterior "solo procederá una vez el senado haya autorizado la declaratoria de guerra"; una vez autorizada y durante el tiempo que se permanezca en el Estado de guerra el "congreso se reunirá con la plenitud de sus atribuciones constitucionales y legales, y al gobierno le informará motivada y periódicamente sobre los decretos que haya dictado y la evolución de los acontecimientos".

Artículo 213 de la C.P durante el Estado de Conmoción Interior el presidente con la firma de sus ministros podrá declarar dicho Estado "por término no mayor de noventa días prorrogable hasta por dos periodos iguales, el segundo de los cuales requiere concepto previo y favorable del senado de la República" Artículo 214 de la C.P respecto al Estado de Guerra Exterior y Conmoción Interior la responsabilidad del presidente y sus ministros se hará efectiva "cuando declaren los Estados de Excepción sin haber ocurridos los casos de Guerra Exterior o Conmoción Interior... o por cualquier abuso que hubieren cometido en el ejercicio de las facultades"... que se le han otorgado. Responsabilidad que se determinará en el juicio político que anteriormente fue descrito. 


\section{REVISTA VIRTUAL VIA INVENIENDI ET IUDICANDI \\ "CAMINO DEL HALLAZGO Y DEL JUICIO"}

http://viei.usta.edu.co/E-MAIL: revistainveniendi@usantotomas.edu.co

Artículo 215 de la C.P cuando ocurran hechos que perturben de forma grave e inminente el orden económico, social y ecológico del país o que constituyan grave calamidad pública podrá el Presidente declarar el Estado de Emergencia, podrá dictar igualmente decretos con fuerza de ley destinados exclusivamente a conjurar la crisis o impedir su extensión. "el congreso examinará hasta por un lapso de treinta días, prorrogables por acuerdo de las dos cámaras el informe motivado que le presente el gobierno sobre las causas que determinaron el Estado de Emergencia..." igualmente el congreso durante el año siguiente a la declaratoria de la emergencia "podrá derogar, modificar o adicionar los decretos a que se refiere este artículo". Al igual que los dos Estados anteriores la responsabilidad del Presidente y los Ministros se presentará cuando declaren el Estado de Emergencia sin cumplir las circunstancias que prevé el artículo y de igual manera se someterán al juicio político.

\section{Decretos de emergencia económica}

Como ya se expuso en capítulos anteriores, la declaración de emergencia económica es una prerrogativa del Ejecutivo, que lo enviste de facultades extraordinarias, en circunstancias que traspasan el límite de lo normal, en los Estados de Excepción suelen entrar en conflicto las razones de Estado, frente a la vigencia del Estado de Derecho. 


\section{REVISTA VIRTUAL VIA INVENIENIDI ET IUDICANDI \\ "CAMINO DEL HALLAZGO Y DEL JUICIO"}

http://viei.usta.edu.co/ E-MAIL: revistainveniendi@usantotomas.edu.co

\section{Solicitud de Informes}

Contemplado en el artículo 135 numeral 3 de la C.P que prevé como función de cada una de las cámaras "solicitar al gobierno los informes que necesite...". En concordancia con el artículo 200 numeral 5 que contempla que el gobierno en relación con el congreso tienen la función de "rendir a las cámaras los informes que estas soliciten sobre negocios que no demanden reserva."

\section{Citaciones}

Establecido en el artículo 135 numeral 8 y 9 de la C.P modificados por el acto legislativo 01 de 2007 en el cual es facultad de las cámaras citar y requerir a los ministros, superintendentes y directores de departamento administrativos para que concurran a las cesiones; citación que deberá formularse por escrito. Igualmente proponen moción de censura a los mismos por funciones relacionadas a sus cargos, por no atender los requerimientos y finalmente no concurrir a las citaciones del congreso de la república. 


\section{REVISTA VIRTUAL VIA INVENIENDI ET IUDICANDI \\ "CAMINO DEL HALLAZGO Y DEL JUICIO"}

http://viei.usta.edu.co/ E-MAIL: revistainveniendi@usantotomas.edu.co

\section{Control Presupuestal}

El artículo 346 de la C.P en materia presupuestal una de las funciones del gobierno con relación al congreso es la formulación "anualmente del presupuesto de rentas y ley de apropiaciones que deberá corresponder al plan nacional de Desarrollo y lo presentará el congreso, dentro de los primeros diez días de cada legislatura".

Es necesario precisar los mecanismos de control que se han establecido tanto en el sistema Parlamentario como en el Presidencial teniendo en cuenta que estos sistemas tienen características específicas que los diferencian, pero conservando el equilibrio y división de poderes como eje fundamental. El fin de los múltiples controles sea en uno o en otro es el mismo; evitar el exceso y concentración de poder. Sin embargo es posible encontrar algún tipo de control, como lo es la moción de censura, originaria en uno de ellos -Sistema Parlamentario- como mecanismo efectivo de control a las actuaciones del Ejecutivo a través de sus ministros de despacho en diferentes países que han optado por el sistema Presidencial. 


\section{REVISTA VIRTUAL VIA INVENIENIDI ET IUDICANIDI}

"CAMINO DEL HALLAZGO Y DEL JUICIO"

http://viei.usta.edu.co/ E-MAIL: revistainveniendi@usantotomas.edu.co

\section{Responsabilidad del Presidente de la República}

En Colombia y en general en Latinoamérica, se ha podido percibir una preocupación creciente por limitar el poder del Ejecutivo, que en ocasiones se considera excesivo. La responsabilidad del ejecutivo es uno de los principios constitucionales, al estar delimitadas sus funciones y competencias en la Constitución se genera automáticamente responsabilidad constitucional. Algunos autores presentan los llamados Procedimientos necesarios para establecer cuando así se requiere responsabilidad frente a los actos del Jefe de Estado. Los procedimientos son dos:

- Justicia Política Penalista

- Justicia Política Constitucional

El primero corresponde ser adelantado por la jurisdicción entre tanto el segundo, tiene como finalidad aplicar sanciones políticas a los funcionarios del gobierno, que comprometan su responsabilidad política. En Colombia la Constitución prevé en su artículo 175, dos clases de procedimientos aplicables a los procesos seguidos en contra del Presidente de la República. 


\section{REVISTA VIRTUAL VIA INVENIENIDI ET IUDICANDI \\ "CAMINO DEL HALLAZGO Y DEL JUICIO"}

http://viei.usta.edu.co/ E-MAIL: revistainveniendi@usantotomas.edu.co

El primero procede cuando el Presidente es acusado de haber cometido delitos durante su mandato, o cuando es acusado de indignidad como consecuencia de mala conducta, en éste caso el Senado, puede imponerle como pena, tanto la destitución del cargo, como la privación temporal o definitiva de sus derechos políticos.

Los delitos no pueden ser juzgados por el Senado, pero es éste quien admite y presenta la acusación ante la Corte Suprema de Justicia, donde es enviado y surtido el trámite procesal. La acusación es presentada por la comisión de acusaciones de la Cámara de Representantes.

El segundo procedimiento, consiste en procesar los delitos comunes cometidos antes de ejercer el cargo, los cuales son juzgados igualmente por la Corte Suprema de Justicia, tras haberse surtido un trámite en el Senado de presentación de declaración acerca de si el Presidente pude ser procesado. Dentro de los procedimientos señalados el Presidente cuenta con un fuero especial, en principio se desarrolla un procedimiento previo en el Congreso encaminado a evitar acusaciones temerarias y permitir el desarrollo normal de la Administración. Luego ya el proceso en la Corte Suprema de Justicia, juzga penalmente al Jefe del Ejecutivo. 


\section{REVISTA VIRTUAL VIA INVENIENDI ET IUDICANDI \\ "CAMINO DEL HALLAZGO Y DEL JUICIO"}

http://viei.usta.edu.co/ E-MAIL: revistainveniendi@usantotomas.edu.co

La comisión de acusaciones e la cámara estudia el caso y si la declaratoria de acusación procede, esta se levanta ante el Senado, éste estudia los cargos y si hay mérito impone la pena, seguida de la declaración de indignidad, es éste procedimiento el que se envía a la Corte Suprema de Justicia para que le Presidente sea procesado penalmente. La responsabilidad política da paso a la responsabilidad penal. Todo procedimiento adelantado en el Congreso en contra del Presidente se ajusta a las normas del procedimiento penal, regido por los principios de tipicidad, anti-juricidad y culpabilidad, esto en lo que tiene que ver con los aspectos jurídicos y frente a los aspectos políticos, no podemos separarnos del carácter subjetivo y discrecional del control político y de la responsabilidad política ya analizadas en pasajes anteriores.

En el sistema presidencial colombiano, el control que ejerce la Rama Legislativa no está llamada a derrocar al Presidente, sino a criticar los errores del Gobierno, produciendo un efecto en la opinión del electorado, por su parte, al contar el Ejecutivo con un periodo fijo de gobierno, no requiere de manera necesaria el apoyo del Congreso, ya que éste no puede emitir un voto de censura, solo puede criticarlo y no apoyar sus iniciativas. Finalmente es el electorado quien juzga ambos órganos, ya que conforme a la Constitución, los dos se integran al ser de elección popular, son representativos del pueblo. Sonia Patricia Cortés

\section{Zambrano}




\section{REVISTA VIRTUAL VIA INVENIENDI ET IUDICANDI \\ "CAMINO DEL HALLAZGO Y DEL JUICIO"}

http://viei.usta.edu.co/ E-MAIL: revistainveniendi@usantotomas.edu.co

\section{CONCLUSIÓN}

\section{El equilibrio y control político en el Estado Constitucional colombiano}

Colombia pasó de un Estado de Derecho a un Estado Social de Derecho, y la organización política dispuesta en la Constitución, ya no solo está sujeta a la ley, sino que tiene la obligación constitucional de promover activamente la realización de los valores constitucionales.

El paso hacia un Estado Constitucional, contribuye notablemente a un cambio en la teoría política, pasando de una concepción competencial del Estado a una concepción axiológica, en donde las disposiciones constitucionales se convierten en principios que requieren de ponderación, la democracia sufre igualmente su transformación, al fortalecerse los procesos de participación, traspasamos la frontera entre una Constitución formal, por la idea de una Constitución material de principios. (ARANGO 2004)

El concepto de control se encuentra íntimamente ligado al concepto de Constitución y así al concepto de Estado Constitucional, concepto último que se funda en el carácter normativo y democrático de la Constitución. El Estado Constitucional es una forma política, y este carácter le imprime la necesidad de 


\section{REVISTA VIRTUAL VIA INVENIENDI ET IUDICANDI \\ "CAMINO DEL HALLAZGO Y DEL JUICIO"}

http://viei.usta.edu.co/ E-MAIL: revistainveniendi@usantotomas.edu.co

consagrar el control al poder político, como un aspecto inseparable de la teoría constitucional.

El Control es un elemento inseparable de la Constitución, al concebírsela en si misma, como un instrumento de limitación al poder (ARAGÓN 1989), y como ya se manifestó, existe una concepción plural del ejercicio del poder, no hablamos ya de una separación estricta del poder, sino de una participación en el poder de lo distintos estamentos. Estas relaciones generan sin duda, la determinación de una serie de controles que pueden evidenciarse entre ellos.

En el Estado Social y Democrático colombiano, consagrado en la Constitución de 1991, se evidencia el establecimiento de mecanismos que indudablemente tienden a fortalecer el control al poder, como por ejemplo el establecimiento de la Corte Constitucional, y algunos de los mecanismos interorgánicos ya mencionados, todos llamados a restringir en forma regular y efectiva el poder.

El establecimiento del Estado Democrático y Social, establece restricciones efectivas al poder, y su surgimiento data a partir de la segunda posguerra mundial. Lo que es útil analizar en este punto, tiene que ver con el carácter social que se le imprime al Estado y que en forma relevante, extiende su poder, aquí es donde cobra importancia el tema del control, el cual se liga íntimamente con el concepto 


\section{REVISTA VIRTUAL VIA INVENIENDI ET IUDICANDI \\ "CAMINO DEL HALLAZGO Y DEL JUICIO"}

http://viei.usta.edu.co/ E-MAIL: revistainveniendi@usantotomas.edu.co

de democracia pluralista, pues en ella se consignan como ya se expresó, el carácter legitimador del poder político.

El Estado Constitucional se basa en el principio de la distribución del poder y éste existe cuando varios detentadores del poder independientes entre sí, participan en la formación de la voluntad estatal y las funciones asignadas se encuentran sometidas a un control que es ejercido a través de los otros detentadores del poder. El constitucionalismo caracteriza a una sociedad estatal, basada en la libertad y la igualdad y que funciona como Estado de Derecho. (LOEWETEIN 1982)

Es necesario mencionar en este momento, por qué hablar de Estado Constitucional, Zagrebelsky (2008 p. 33), propone al Estado Constitucional como un "auténtico cambio genético", respecto de los postulados del Estado de Derecho. A diferencia de García Pelayo (1991) quien afirma que el Estado Constitucional perfecciona al Estado de Derecho, y que existe una natural relación de continuidad entre ellos. En efecto el Estado de derecho, organiza políticamente al Estado, y somete el poder al derecho de manera formal, atendiendo al conjunto de disposiciones tendientes a garantizar el control jurídico del poder, tales como, separación de poderes, principio de legalidad, control judicial, reconocimiento de derechos, y de manera sustancial, atendiendo propiamente a los contenidos normativos que condicionan el actuar del poder, sus derechos y obligaciones. 


\section{REVISTA VIRTUAL VIA INVENIENDI ET IUDICANDI \\ "CAMINO DEL HALLAZGO Y DEL JUICIO" \\ http://viei.usta.edu.co/ E-MAIL: revistainveniendi@usantotomas.edu.co}

Es importante señalar que la diferencia entre el Estado Constitucional y el Estado de Derecho, se da de manera relevante en el alcance que se confiere a los mecanismos de control del poder, todas ellas enmarcadas en un ideario político, sin alcance ni fuerza normativa, un texto político propio del Estado de Derecho. Por su parte el Estado Constitucional leído en las disposiciones constitucionales de la Constitución Política de Colombia de 1991, se fundamenta de la soberanía y de la democracia, compatibles en todo caso con la limitación del poder de las mayorías. Por otra parte, Ilena de contenido normativo a sus disposiciones en la medida en que dispone a la Corte Constitucional, como el defensor de la constitución y con ella a todo el cuerpo de jueces que actúa $\mathrm{n}$ su momento como juez constitucional, dejando de lado ese texto muerto, y dándole poder vinculante a la totalidad del texto constitucional.

Colombia se presenta constitucionalmente como un Estado Social de Derecho, y es importante señalar aquí que el carácter social, pretende hacer compatibles la libertad y la igualdad, lo cual supone la adopción de medidas públicas a favor de grupos sociales en desventaja, basados en criterios de igualdad sustancial.

El Estado Social de Derecho responde a un concepto ético: procurar la igualdad de oportunidades con respecto al acceso a los bienes básicos, para la subsistencia del ser humano en razón de su dignidad como persona. La expresión Estado Social de Derecho, arranca del constitucionalismo alemán (Ley 


\section{REVISTA VIRTUAL VIA INVENIENDI ET IUDICANDI \\ "CAMINO DEL HALLAZGO Y DEL JUICIO" \\ http://viei.usta.edu.co/E-MAIL: revistainveniendi@usantotomas.edu.co}

Fundamental de BONN 1949) posterior a la primera guerra mundial, desarrollado en Europa entre los años 1920 a 1970. A partir de la década de los setenta del siglo $\mathrm{XX}$, al triunfar las ideas neoliberales, se empieza a cuestionar el modelo de Estado Social y se comienza su desmonte en las democracias occidentales. (ECHEVERRI 2002). Entre las circunstancias que dieron paso al Estado Constitucional se destacan:

Los cambios en la representación parlamentaria inclusión de movimiento obrero, partidos de masa, supresión del voto censitario, lo cual quiebra la hegemonía burgués; irrupción progresiva del pluralismo político, alimentado ahora con el discurso del multiculturalismo y minorías, pérdida de la eficacia instrumental de la ley en términos de certeza (seguridad jurídica), libertad e igualdad; y la generación de un pensamiento neoiusnaturalista, de tal manera que todo hace tornar la mirada a la Constitución, es así como en un tiempo la ley era la medida exclusiva de todas las cosas, y ahora cede el paso a la Constitución, convirtiéndose en objeto de medición. (ZAGREBELSKY 2008)

Retomo entonces en este momento la importancia del Control al poder en un Estado Constitucional, viéndolo como una de sus características, ya que éste se puede verificar en el carácter normativo de la Constitución el cual está llamado a asegurar el control, la responsabilidad y la cooperación, su existencia y efectividad. 


\section{REVISTA VIRTUAL VIA INVENIENDI ET IUDICANDI \\ "CAMINO DEL HALLAZGO Y DEL JUICIO"}

http://viei.usta.edu.co/ E-MAIL: revistainveniendi@usantotomas.edu.co

La actividad de la Corte Constitucional, y en consecuencia la aplicación de los jueces constitucionales en aplicación de la Constitución, es tan solo una de las facetas, en el sistema de control al poder, actividad que será analizada en capítulos posteriores.

La Constitución pone de manifiesto el doble carácter instrumental y legitimador del Derecho, en la medida en que no solo comprende la fijación de los fines del poder, sino también la regulación de su estructura de manera congruente con los fines pretendidos. Debe anotarse que la fuerza normativa de la Constitución descansa precisamente en la soberanía popular, en el principio democrático, que por sí mismo es un punto de referencia al momento de interpretar el contenido de la Constitución y limitar el poder.

La relevancia de éste análisis descansa precisamente en la dualidad en la representación política, operando independientemente, legislativo y ejecutivo, la legitimación directa de ejecutivo y de legislativo, propia del sistema presidencial colombiano y su respectiva autonomía política, pueden influir en esta debilidad en el sistema de controles, lo que deja un importante campo de influencia al control por parte del electorado. 


\section{REVISTA VIRTUAL VIA INVENIENDI ET IUDICANDI \\ "CAMINO DEL HALLAZGO Y DEL JUICIO"}

http://viei.usta.edu.co/ E-MAIL: revistainveniendi@usantotomas.edu.co

\section{b. Relaciones de cooperación e interdependencia ¿colaboración armónica?}

Es necesario examinar una serie de factores, para determinar la incidencia en las relaciones que se dan entre el Gobierno y el Congreso, influenciadas por un sistema electoral y de partidos que sin duda repercuten en lo que se denomina la gobernabilidad que es el término que enmarca las relaciones entre éstos dos órganos de poder, que son eficientes y positivas para el país.

En primer lugar se revisan los dos escenarios que nos permiten enmarcar la gobernabilidad como evidencia de relaciones de cooperación y colaboración armónica entre los dos poderes estudiados, el primer escenario se configura cuando los partidos que conforman el poder legislativo, son del mismo grupo o coalición del gobierno, lo cual permite una mayor eficiencia en la actividad legislativa y en la gestión gubernamental, lo que depende a su vez sin duda de la existencia de partidos fuertes, disciplinados, permanentes, ante la ausencia de estas especificidades, partidos fraccionados, que no respondan a una estructura fuerte, con ideología determinada, funcionarían como partidos débiles minoritarios, que no realizan eficazmente ni coalición gubernamental ni oposición seria. Tal y como pasó con los tres gobiernos liberales anteriores al Gobierno de Pastrana, lo cual se analizará más adelante. (Pizarro León Gómez, 2001. p. 122) 


\section{REVISTA VIRTUAL VIA INVENIENDI ET IUDICANDI \\ "CAMINO DEL HALLAZGO Y DEL JUICIO" \\ http://viei.usta.edu.co/E-MAIL: revistainveniendi@usantotomas.edu.co}

El segundo escenario se presenta cuando el partido mayoritario o la coalición de partidos que dominan en el parlamento es diferente a aquel al que pertenece el Presidente, evento que puede provocar un constante poder dividido, un obstáculo a la gestión gubernamental, conflicto entre Congresistas, entre bancadas y el gobierno, que pueden general en tiempos de crisis parálisis institucional. Un Gobierno así debilitado, para poder sacar adelante sus proyectos y políticas de gobierno, se ve obligado a negociar y formar alianzas forzadas, lo cual debilita en sí mismo el sistema político, genera crisis institucional, deslegitimidad y pérdida de credibilidad.

En cualquiera de los dos escenarios presentados se vulnera necesariamente el principio constitucional de equilibrio en el ejercicio del poder político, en la medida en que se privilegian uno $u$ otro, Gobierno o Congreso, con la ya conocida consecuencia de incapacidad de dar respuesta a las necesidades de la ciudadanía y carencia de gobernabilidad. Tal y como se concibe la política en la actualidad, más administración que política, es evidente que se ha ahondado la brecha del desequilibrio entre los poderes públicos del Estado Constitucional Colombiano.

El balance o equilibrio entre los órganos detentadores del poder, sirvió de fundamento a los verdaderos principios de un Estado Constitucional, la Constitución de 1991 señala la colaboración armónica no solo entre las ramas del poder público sino entre los diferentes órganos del Estado, incluyendo los órganos 


\section{REVISTA VIRTUAL VIA INVENIENDI ET IUDICANDI \\ "CAMINO DEL HALLAZGO Y DEL JUICIO"}

http://viei.usta.edu.co/ E-MAIL: revistainveniendi@usantotomas.edu.co

independientes y autónomos, se entiende como "Colaboración Armónica" la conveniente proporción y correspondencia de unas cosas con otras. Estamos ante un equilibrio entre las funciones.

La colaboración armónica, en términos de coordinación y control, como principio constitucional, obedece al deber de cumplimiento de los deberes del Estado. Esto implica que las funciones de cada órgano y no son exclusivas, rígidas e impermeables, las ramas y órganos del Estado, al lado de sus funciones iniciales, desempeñan algunas funciones típicas de otras ramas y órganos. Se rompe la matriz órgano-función (Sentencia C-449/92 Corte Constitucional).

El artículo 113 de la Constitución de 1991, dispone la separación de las Ramas del poder público, cuyos poderes son imitados y opera entre ellos la colaboración armónica. La iniciativa legislativa muestra la colaboración coordinada entre Gobierno y Congreso, ya que se realiza en ella el ejercicio concreto del gobierno. Existe relación de coordinación en la elaboración de las leyes Marco, ya que implica una distribución de los poderes y facultades legislativas entre el Gobierno y el Congreso, el Congreso consagra los preceptos generales y el Presidente expide los decretos ejecutivos, destinados a reglamentar los asuntos a que se refiera la ley. A través de la ley marco, el Congreso señala una serie de lineamientos y orientaciones a los cuales debe atenerse el ejecutivo en su función interventora, es decir, la ley marco establece unos objetivos y criterios generales, los cuales 


\section{REVISTA VIRTUAL VIA INVENIENDI ET IUDICANDI \\ "CAMINO DEL HALLAZGO Y DEL JUICIO" \\ http://viei.usta.edu.co/ E-MAIL: revistainveniendi@usantotomas.edu.co}

deberán ser desarrollados por el ejecutivo a través de su facultad reglamentaria. (Sentencia C-428 de 1997 Corte Constitucional)

El equilibrio de poderes proviene del mencionado contrapeso, el cual no se queda solo en el plano teórico, el modelo de Checks and Balances es ante todo empírico y funcional. (ARAGÓN 1998.). El control y la colaboración son actividades que propenden por una armoniosa colaboración entre Gobierno y Congreso, pero si se evidencia la ineficacia del control dispuesto en la Constitución el sistema de equilibrio se desestabiliza. El conflicto entre el gobierno y el congreso es natural, al encontrarnos ante un ordenamiento de autoridad compartida. La Tensión es también inherente a la política de partidos, y es también normal que tienda a develarse en estas relaciones la cooperación.

Los problemas en el ejercicio del poder que generan vulneración al principio de equilibrio del poder, se enmarcan en las disposiciones constitucionales ambiguas e ineficaces, la manera como se desarrolla la actividad electoral, los periodos en el poder y las reelecciones, la debilidad de los partidos políticos, y el poder vacilante del Congreso que obedece a su relación con el Gobierno. La Constitución confiere al Congreso la facultad legislativa y al Ejecutivo la posibilidad de vetar las leyes, o recomendarlas, como ya se mencionó capítulos atrás, el juicio político, raramente empleado es un freno sobre el presidente, en el Estado Constitucional Colombiano, se separan los poderes restringiendo las facultades de cada rama del 


\section{REVISTA VIRTUAL VIA INVENIENDI ET IUDICANDI \\ "CAMINO DEL HALLAZGO Y DEL JUICIO"}

http://viei.usta.edu.co/ E-MAIL: revistainveniendi@usantotomas.edu.co

poder público, requirió la cooperación entre ellas a fin de realizar un Gobierno Eficaz y esta idea es el fundamento del conflicto.

El conflicto obedece indudablemente a la forma como son elegidos en Colombia el Presidente de la República y los Representantes del Congreso. Reeligen en forma independiente, el primero tiene la defensa de interese nacionales y los segundos regionales, aspecto que puede sugerir contraposición de intereses.

En Colombia a raíz de la posibilidad de Reelección Presidencial, el Ejecutivo cuenta con periodos de cuatro u ocho años, para desarrollar sus programas, sus prioridades se enmarcan en las políticas do orden nacional, a las cuales se dedican en los primeros años, con miras a mantener su popularidad de cara a una posible reelección. Los congresistas tienen un periodo de 4 años, y actúan con más lentitud, debido a los vastos intereses locales que representa. La duración de los mandatos de Gobierno y Congreso causa una diferencia en el curso de toma de decisiones, esto genera en ocasiones conflicto y estancamiento de propuesta legislativas que pueden generar políticas públicas necesarias para la sociedad.

Los partidos políticos débiles, con problemas de democracia interna, de ideología e ideario político, no generan confianza en el electorado, no están llamados a ser permanentes, no se subordinan a los fines sociales, roban la legitimidad de las instituciones políticas y son éstos los que componen las bancadas en el Congreso, 


\section{REVISTA VIRTUAL VIA INVENIENDI ET IUDICANDI \\ "CAMINO DEL HALLAZGO Y DEL JUICIO"}

http://viei.usta.edu.co/ E-MAIL: revistainveniendi@usantotomas.edu.co

debilitándolo y dejándolo a la deriva en manos de quien si se encuentra legitimado y fortalecido : el Gobierno, tal es la situación que, el último gobierno presidencial en Colombia, liderado por Uribe Vélez, ha estado apartado de identificarse con algún partido o movimiento político, ha triunfado el liderazgo frente a la democracia, sin duda alguna.

El problema trata de ser erradicador por la ley de bancadas y la reforma de 2003, buscando el fortalecimiento de los partidos políticos y la activación de su funcionalidad, según los parámetros que definen y caracterizan a los partidos políticos según la ciencia política. Llama la atención como de alguna manera el acentuar el tema de controles recíprocos, hace que se examine la eficiencia y eficacia de las decisiones y sus planes estratégicos, lo cual es un punto a favor en el proceso de construcción de políticas públicas, las cuales son en realidad, el punto decisivo de la política. Es claro que cuando el gobierno tiene la mayoría del congreso a su favor o son de la misma corriente política se favorecen los procesos de cooperación, pero como ha demostrado la realidad, no es éste un factor que destierre el conflicto entre ellos.

Los aspectos que siempre van a asegurar confrontación entre Gobierno y Congreso, son la representatividad, la eficiencia, apertura y responsabilidad, intereses específicos y bien público. Ello se debe a que el presidente debe encontrar apoyo en el Congreso y el Congreso busca la asistencia del Gobierno 


\section{REVISTA VIRTUAL VIA INVENIENDI ET IUDICANDI \\ "CAMINO DEL HALLAZGO Y DEL JUICIO"}

http://viei.usta.edu.co/E-MAIL: revistainveniendi@usantotomas.edu.co

en cabeza del Presidente; el buen gobierno se da cuando se establece una relación que funcione entre estos dos estamentos de poder. Por tanto la separación de poderes, la división del control político nunca es una barrera para la determinación de buenas políticas públicas, pues ellas se basan precisamente en la negociación, en el poder de negociación y allí se evidencia quien ejerce en mayor y menor grado el poder político.

Se destaca como positivo en el enfrentamiento entre las ramas del poder público, el ejercicio del control, ya que el ejercicio del poder en manos de un representante mayoritario, podría socavar los intereses y derechos de las minorías, y a partir de allí, la confrontación permite que los cambios de gran envergadura política, se adelantaran solo con un gran consenso. Como negativo se destaca la obstaculización al proceso de gobernabilidad, un gobierno detenido, sin producción relevante, desgastado y con pocos resultados, instituciones desgastadas que deben someterse al ejercicio de la responsabilidad política. Impera el fortalecimiento de los partidos, la construcción de partidos políticos fuertes, reforzar el sistema de partidos, permitir la acción concertada del partido mayoritario y permitir el ejercicio del principio pluralista en el ejercicio de la democracia.

En el Estado Constitucional Colombiano que ostenta una Constitución de consenso, los parámetros más fuertes impuestos por el pensamiento neoliberal, 


\section{REVISTA VIRTUAL VIA INVENIENDI ET IUDICANDI \\ "CAMINO DEL HALLAZGO Y DEL JUICIO"}

http://viei.usta.edu.co/E-MAIL: revistainveniendi@usantotomas.edu.co

que por su puesto no excluyen la intervención del Estado, requiere de coherencia y centralización en las decisiones políticas estratégicas. Tal necesidad ha conducido al debilitamiento de los órganos legislativos y de los gobiernos regionales (ECHEVERRI 2002), en beneficio del acrecentamiento de las facultades del Ejecutivo, rompiéndose el esquema clásico de la igualdad y el equilibrio de las ramas del poder haciendo más que nunca necesario el efectivo control del poder político que recae en cabeza del Ejecutivo en virtud a su gran potestad decisoria.

En su totalidad, tal como lo afirmara Loewestein (1982 p.132), el mecanismo del poder se presenta como la interdependencia de los distintos detentadores del poder por coordinación, en el régimen presidencial. Lo anterior obedece a que existe una autonomía entre las ramas del poder público, dentro de la esfera de competencias que se les ha asignado constitucionalmente, lo cual implica una distribución del poder. Sin embargo es necesaria la cooperación en puntos de encuentro que se establecen previamente.

Los puntos de encuentro para la cooperación entre Gobierno y Congreso, precisamente los prescritos constitucionalmente como por ejemplo la dirección de la economía, constituyen puntos estratégicos del proceso político. Extraconstitucionalmente, es claro que el presidente influye en la bancada de gobierno en el Congreso y la actividad legislativa y de control, a su vez el congresista o la 


\section{REVISTA VIRTUAL VIA INVENIENDI ET IUDICANDI \\ "CAMINO DEL HALLAZGO Y DEL JUICIO"}

http://viei.usta.edu.co/E-MAIL: revistainveniendi@usantotomas.edu.co

bancada puede influir en la designación, nombramiento o postulación para determinados cargos, entre otros encuentros que se dan en el desarrollo de la actividad política.

El Criterio de distribución de competencias y funciones así como la concentración de poder debe examinarse a la luz de todas las fases del proceso gubernamental, precisamente el análisis de las relaciones entre Gobierno y Congreso, en el marco del Control Político, parte de estos encuentros entre las dos ramas de poder público en el marco jurídico constitucional y extra-constitucional a las que ya se ha hecho referencia en capítulos anteriores, estas relaciones son propias del tipo de gobierno presidencial y podría afirmar, basado en los argumentos ya expuestos, que nos encontramos en una relación de poderes que ha fortalecido la figura del Ejecutivo, inclinando la balanza de equilibrio del poder hacia el Gobierno.

Si bien la Constitución de 1991, intentó retirar los poderes excesivos en cabeza del ejecutivo, y generar espacios de control político eficaz a partir del fortalecimiento de las instituciones democráticas, de los partidos, y de las funciones del Congreso y otros órganos de control, la realidad escapa a ésta pretensión, la respuesta podría darse en el sentido que el Gobierno ha sido eficiente en sus políticas a punto de tener no solo el aval de un electorado sino el aval frente a sus políticas por la mayoría del Congreso, a punto de transformar una 


\section{REVISTA VIRTUAL VIA INVENIENDI ET IUDICANDI \\ "CAMINO DEL HALLAZGO Y DEL JUICIO"}

http://viei.usta.edu.co/ E-MAIL: revistainveniendi@usantotomas.edu.co

de las características constitucionales de la forma de gobierno presidencial establecido en la Constitución colombiana, como la no reelección presidencial.

\section{a. El Hiperpresidencialismo en Colombia}

En este orden de ideas se presenta la existencia de un HIPERPRESIDENCIALISMO en Colombia, fuerte desde siempre y basado principalmente en la debilidad o inexistencia de sistema de partidos, y la debilidad institucional del Congreso, que se ha fundamentado en argumentos expuestos en capítulos anteriores. El Hiperpresidencialismo se enmarca dentro de lo que algunos doctrinantes han denominado el neopresidencialismo, el Hiperpresidencialismo se define como el predominio a veces desmedido, de poder ejecutivo frente al poder legislativo, lo cual representa una alteración al principio tradicional del Estado Constitucional y de Derecho que corresponde a la división funcional y equilibrio del poder político.

En los debates de la Asamblea Nacional Constituyente, surgió el tema del Hiperpresidencialismo, el cual fue caracterizado por la acumulación, en la figura del presidente de la República, considerado como el eje motor de todo el régimen, todas las facultades, constituyendo una forma "monstruosamente" desequilibrada en el ejercicio del poder a través de los poderes públicos, lo que implica un enorme esfuerzo en la consolidación de un sistema efectivo de pesos y 


\section{REVISTA VIRTUAL VIA INVENIENDI ET IUDICANDI \\ "CAMINO DEL HALLAZGO Y DEL JUICIO"}

http://viei.usta.edu.co/ E-MAIL: revistainveniendi@usantotomas.edu.co

contrapesos, y de control al poder político del Congreso al Gobierno. (ASAMBLEA NACIONAL CONSTITUYENTE Comisión Tercera 1991 p. 31) Uno de los hechos que genera el Hiperpresidencialismo en un país, es la fragmentación social y política de un Estado, evidente en la crisis en el sistema de partidos, la no concurrencia de los ciudadanos a las urnas, el conflicto armado, la desacertada administración de los sistemas electorales, la crisis democrática en representatividad y participación, la fragmentación en las decisiones en la labor legislativa, y la crisis institucional del congreso y la justicia.

Necesariamente para que exista una relación armónica entre el Gobierno y el Congreso es necesario impedir la concentración de poder en alguna de ellas, en especial en el Ejecutivo, lo cual genera inevitablemente la vulneración a la estabilidad democrática y política del país. En Colombia el desempeño del Gobierno de Avaro Uribe, con su proceso reeleccionista y la operatividad del régimen de Bancadas en el Congreso, develan que la democracia depende casi en su totalidad del presidente, como acto decisivo. Estamos en la política dirigida por un solo hombre, que sabe presentar sus decisiones, con estilo característico y con un variado éxito, revelando destreza política dentro y fuera de los límites constitucionales.

Se personaliza el poder, el mandato presidencial pasa de ser fijo a ser indefinido, fundado en la continuidad de un buen gobierno, basado en las amplias facultades 


\section{REVISTA VIRTUAL VIA INVENIENDI ET IUDICANDI \\ "CAMINO DEL HALLAZGO Y DEL JUICIO"}

http://viei.usta.edu.co/ E-MAIL: revistainveniendi@usantotomas.edu.co

que ya estudiamos y enfrentado a un Congreso visiblemente debilitado, deslegitimado ante los ciudadanos y que colabora eficientemente con las políticas gubernamentales.

Dentro de los aspectos que nos permiten hablar de Hiperpresidencialismo en Colombia tenemos: el poder ejecutivo concentra una importante cantidad de recursos políticos y de negociación con la cual gerencia el Estado, centra su política en decidir que es lo que necesita con urgencia la nación "seguridad democrática", y sus políticas y trabajo se dirige a ello, ha aprovechado las oportunidades que se le presentan para consolidar la autoridad presidencial c través del acercamiento a la población y sus problemáticas a través de los concejos comunales, y el adelanto de políticas eficientes en el campo económico que muestran crecimiento, finalmente presenta ante la opinión la incomprensión de la oposición sobre su tipo de política que a través de las coaliciones ha generado amplios procesos de gobernabilidad.

El aumento de periodo presidencial por su parte, a ocho años y tal vez ante una futura reforma que permita la reelección indefinida, la facultad del presidente de coordinar la actividad del gobierno con las otras ramas del poder público, la relación cercana que se crea con el Banco de la República a través de la reelección, la dirección de las fuerzas armadas, inclinan sin duda la balanza hacia la rama del poder ejecutivo en Colombia. 


\section{REVISTA VIRTUAL VIA INVENIENDI ET IUDICANDI \\ "CAMINO DEL HALLAZGO Y DEL JUICIO"}

http://viei.usta.edu.co/ E-MAIL: revistainveniendi@usantotomas.edu.co

Dentro de otros factores que inciden en la concentración del poder en cabeza del presidente están: sistema empresarial y no democrático de gobierno, estado de Legitimidad de las instituciones políticas, implementación del régimen de bancadas: en unos casos la forma eficaz de legitimar los actos del gobierno y en otros la inoperancia al interior del Congreso, debido al mantenimiento de la idea personalista y caudillista del parlamentario, que fracciona la actividad parlamentaria y resquebraja su eficiencia.

\section{b. Predomino presidencial y el Congreso}

Durante el siglo XX, los presidentes han tenido un significativo aumento de poder, pero ello no es prueba de su hegemonía en el sistema político, en Colombia la ley de bancadas que constituye una importante transformación del poder del Congreso, y el principio de separación y equilibrio del poder, constituyen una importante limitante a esta supuesta hegemonía del presidente de la república. El fortalecimiento de la figura presidencial y con ella del gobierno no es signo protagónico de los últimos tiempos en Colombia o Latinoamérica exclusivamente, sino que incluso ha llegado a traspasar las fronteras de los países con régimen parlamentario, en donde la figura del primer ministro se ha impregnado de este papel protagónico en la funcionalidad del sistema político. La importancia del presidente radica en las expectativas del electorado, la figura presidencial se ve desde la perspectiva progresista, el presidente como conductor activo de un 


\section{REVISTA VIRTUAL VIA INVENIENDI ET IUDICANDI \\ "CAMINO DEL HALLAZGO Y DEL JUICIO"}

http://viei.usta.edu.co/ E-MAIL: revistainveniendi@usantotomas.edu.co

electorado complejo, plural, nacional y las expectativas públicas se dirigen a la actividad presidencial, pues se considera de mayor impacto a la desplegada por el Congreso.

En Colombia la imagen presidencial jugaba en torno de la legitimidad de los partidos y su capacidad burocrática, sin embrago, en el caso particular del Gobierno Uribe, su independencia partidista, le ha permitido mantenerse al margen de la crisis institucional que les ronda, y consolidarse como un líder importante. La tesis es que quienes tengan aspiraciones presidenciales deben depender cada vez menos de los partidos políticos, y más de sus recursos y popularidad. Esta independencia le permite al gobierno, negociar con las bancadas independientemente del partido o el ideario político que representen. La organización de coaliciones gubernamentales se reduce al poder de negociación del Presidente de la República con las Bancadas del Congreso.

Es en éste sentido precisamente, que la reforma política de 2003 y la consecuente ley de bancadas, presenta mecanismos para reforzar el control al ejecutivo, para buscar un restablecimiento del equilibrio del poder, reformando los procedimientos institucionales, debilitando el sistema de jerarquías y patronazgos, burocracia y haciendo pública la actividad del Congreso para la transparencia y la recuperación de la legitimidad y la valoración de la actividad desplegada por el Congreso de la 


\section{REVISTA VIRTUAL VIA INVENIENDI ET IUDICANDI \\ "CAMINO DEL HALLAZGO Y DEL JUICIO"}

http://viei.usta.edu.co/ E-MAIL: revistainveniendi@usantotomas.edu.co

República, con miras, entre otras cosas, de limitar la influencia del Gobierno sobre. el Congreso.

Lo claro es que para que se puedan adoptar y adelantar políticas públicas coherentes, eficaces y oportunas, el Gobierno y el Congreso, deben estar de acuerdo, cuando la coalición, o el mismo partido, controla estos dos centros de poder, existe un ánimo fuerte de acuerdo, pese a los celos y rivalidades propias de cada institución, es entonces el partido quien debe tornar a su papel fundamental en el sistema político, de mediador entre los intereses sociales y el poder, para hacer eficaz la acción del Estado Constitucional en cumplimiento de sus deberes.

A lo largo de los años el Congreso ha sido atacado por variadas razones, entre ellas, su naturaleza como organización fragmentada con electorados localistas, y sus desacuerdos con gobiernos que han gozado de cierta popularidad. El poder al interior del congreso es fragmentado, su ejercicio obedece a intereses particulares de Congresistas y ahora de bancadas, que responden a necesidades ocales. Esta dispersión de la autoridad en el Congreso, deja que el poder se fugue hacia la rama ejecutiva, hacia el Gobierno. Este fenómeno así como la evasión a la responsabilidad, hace que el Congreso en la mayoría de las veces delegue su autoridad al Presidente, la toma de decisiones en materia de políticas públicas las toma el Gobierno en alianza negociada, o cuando son asumidas por el Congreso, se evidencia su carácter personal y burocrático. 


\section{REVISTA VIRTUAL VIA INVENIENDI ET IUDICANDI \\ "CAMINO DEL HALLAZGO Y DEL JUICIO"}

http://viei.usta.edu.co/ E-MAIL: revistainveniendi@usantotomas.edu.co

Las legislaturas tienden a ser influenciadas y no especializadas, dispersas, los Congresistas tienen mayor papel representativo que de afirmación de políticas, contrario al ejecutivo, tienden a ser especializados, jerárquicos y organizados de tal manera que producen políticas públicas coherentes y eficaces a la luz de la opinión pública.

Así como el ejecutivo no se encuentra libre de faltas en el ejercicio del poder, tampoco lo está el Congreso, éste afirma en ocasiones su poder de control de tal forma, que interfiere con la capacidad del ejecutivo para ejercer en forma eficaz el gobierno, pero alguna veces actúa tan tímidamente y en forma fragmentada, que simplemente genera que el ejercicio del poder político se perciba realizado, en gran medida, solo por el poder ejecutivo.

\section{El Pluralismo como control político en la dinámica del poder}

Los destinatarios del poder, que son la multitud de grupos que presentan colectivamente la variedad infinita de los intereses de los miembros en la comunidad estatal. La sociedad de masas de hoy se caracteriza por el pluralismo cuyas características fueron ya abordadas en un capítulo anterior. El liderazgo del poder se asigna constitucionalmente a los detentadores del poder: Gobierno, Congreso y Electorado, se espera que quienes ejercen el poder mediante sus decisiones armonicen los intereses contrapuestos de los grupos pluralistas en 


\section{REVISTA VIRTUAL VIA INVENIENDI ET IUDICANDI \\ "CAMINO DEL HALLAZGO Y DEL JUICIO"}

http://viei.usta.edu.co/ E-MAIL: revistainveniendi@usantotomas.edu.co

beneficio común de la sociedad. Como los grupos pluralistas influyen en la toma de decisiones, y por tanto en el ejercicio del poder, son detentadores invisibles del poder (LOEWENSTEIN 1982).

A continuación veremos cómo operan los grupos pluralistas y el papel que juegan en la transformación de los procesos democráticos.

\section{c. La democracia, la participación y la oposición en la función de control al poder en Colombia}

Se parte de la premisa: la libertad es incompatible con el poder absoluto, la libertad de los ciudadanos solo se garantiza si el poder es limitado. El Estado Constitucional tiene como base la democracia representativa y hace descansar su estructura en el equilibrio del poder. Aragón (2002) afirma, la división del poder implica distribución de potestades y de competencias, y es esta distribución la que está llamada a garantizar la limitación, y ésta solo se hace efectiva a través de criterios materiales que en este caso corresponden a las divisiones que corresponden al Estado Constitucional.

Divisiones que en un primer lugar ubican al poder constituido (órganos del poder organizados por competencias (legislar, gobernar, juzgar), del poder constituyente (el poder de cambiar la constitución o de generar una nueva). Por tanto al unísono 


\section{REVISTA VIRTUAL VIA INVENIENDI ET IUDICANDI \\ "CAMINO DEL HALLAZGO Y DEL JUICIO"}

http://viei.usta.edu.co/ E-MAIL: revistainveniendi@usantotomas.edu.co

con el autor, se afirma, que el poder que se divide, es un poder limitado en sentido formal y en sentido material, de ésta forma se advierte también que el control es un elemento inseparable no solo de la constitución, sino también del concepto de Democracia.

Son los destinatarios del poder quienes se encuentran llamados a controlar efectivamente el poder, el pluralismo se convierte en la herramienta más efectiva de lucha a favor de la democracia, es así como un grupo de ciudadanos unido por intereses comunes como los nuevos actores de la democracia en tiempos globales, pueden hacer presión en la toma de decisiones.

Finalmente, uno de los factores que incrementa el poder del Ejecutivo tiene indudablemente que ver con el manejo de las relaciones internacionales y la toma de decisiones frente a otros gobiernos y organismos internacionales, actuaciones que por lo general cuentan con el aval del Congreso y de la Corte Constitucional. Aquí el Presidente tiene un amplísimo margen decisorio, pero el pueblo puede entrar a participar de estas negociaciones que hoy por hoy enmarcan el desarrollo del Estado y su nuevo papel en el cual sin duda el Ejecutivo se encuentra llamado a desempeñar un papel de gran relevancia.

Es por eso que, ya en la parte final de éste estudio, la cual queda apenas enunciada y abierta para un estudio más profundo, se aborda el tema de la 


\section{REVISTA VIRTUAL VIA INVENIENIDI ET IUDICANDI \\ "CAMINO DEL HALLAZGO Y DEL JUICIO"}

http://viei.usta.edu.co/ E-MAIL: revistainveniendi@usantotomas.edu.co

Democracia y la Oposición, y su importancia en el desempeño en pro del fortalecimiento del principio de equilibrio el poder, de control del poder y en la toma de decisiones a través de los actos de presión, en defensa de intereses sociales. Sonia Patricia Cortés Zambrano

\section{REFERENCIAS BIBLIOGRÁFICAS}

1. ALGORRI J. (2001). Democracia y gobernabilidad. México. Ed. UNAM

2. ARAGON M. (1998). Constitución, Democracia y Control. Mexico. Ed. UNAM, Instituto de investigaciones jurídicas.

3. ARAGÓN M. (1995). Constitución y Control del Poder. Introducción a una teoría constitucional del Control. Argentina. Ed. Ciudad Argentina. Buenos Aires.

4. ARANGO R. (2004), Derecho, Constitucionalismo y Democracia. Bogotá. Ed. U. Externado.

5. ARIÑO ORTIZ G. (1999). Principios de Derecho Público Económico. Colombia. Ed. U. Externado.

6. ARISTÓTELES, La Política. Bogotá. Ed. Talleres Gráficas Modernas. (libro VI, capítulo XI )

7. BAUTISTA D. (2006), Función Constitucional de los partidos políticos. España Ed. Comares. U. de Granada. 


\section{REVISTA VIRTUAL VIA INVENIENDI ET IUDICANDI \\ "CAMINO DEL HALLAZGO Y DEL JUICIO"}

http://viei.usta.edu.co/ E-MAIL: revistainveniendi@usantotomas.edu.co

8. BEJARANO, A. (2001). ¿Qué hace funcionar al Congreso? Bogotá. Universidad de los Andes.

9. BERNAL C. (2007). Democracia y Globalización en América Latina. En El derecho en el contexto de la globalización. Editor Gonzalo Ramírez. Bogotá. Ed. U. Externado.

10. BERNAL C. (2007) Democracia y Globalización en América Latina. En El derecho en el contexto de la Globalización. Bogotá. Ed. U Externado.

11. BERNNAN G. (2007). Globalización y diversas formas de democracia. En La Globalización y el Orden Jurídico. Colombia. Ed. U Externado. Colombia.

12. BOBBIO N. (1996). El futuro de la democracia. Mexico. $2^{-a}$ ed. Trad. José Fernández, Fondo de cultura económica.

13. BODIN J. Los Seis Libros de la República. España. Ed. Tecnos Madrid.

14. BUENAHORA J (2002). Por qué es necesaria una reforma política general. Bogotá. en CIDE. Ed. Opera 2001, U Externado P.33-70?.

15. CARBONELL M, y VÁSQUEZ R. (coordinadores) (2007). La Globalización y el Orden Jurídico. Reflexiones Contextuales. Colombia. Ed. U Externado. Colombia. 16. CÁRDENAS M (2005). La reforma Política del Estado en Colombia: Una salida integral a la crisis. Bogotá. Fondo Editorial CEREC.

17. CARPIZO J. (2004). Algunas reflexiones constitucionales. Mexico. UNAM.

18. CEPEDA M. (1993). Introducción a la Constitución de 1991. Hacia un nuevo constitucionalismo. Colombia. Ed. Imprenta Nacional de Colombia. 


\section{REVISTA VIRTUAL VIA INVENIENDI ET IUDICANDI \\ "CAMINO DEL HALLAZGO Y DEL JUICIO"}

http://viei.usta.edu.co/ E-MAIL: revistainveniendi@usantotomas.edu.co

19. CONTRERAS M. (2004). Ciudadanía Estado y Democracia en la era Neoliberal. En Daniel Matto Coord. Políticas de Ciudadanía y Sociedad Civil en tiempos de globalización. Venezuela. Ed. FACES Universidad Central de Venezuela.

20. DAHL R. (1999) La democracia una guía para los ciudadanos. Madrid Ed. Taurus.

21. DE AGAPITO SERRANO R. (1989). Libertad y División de Poderes. Madrid. Ed. Tecnos.

22. DE AQUINO Tomás. Suma Teológica sección primera de la segunda parte, cuestión xcv art. 1

23. DE LA CUEVA M. (1982). Teoría de la Constitución. México. Ed. Porrua S.A.

24. DUVERGER M (1980). Instituciones Políticas y Derecho Constitucional. España. Ed. Ariel Barcelona

25. ECHEVERRI A. (2002). Teoría Constitucional y Ciencia Política Bogotá. Ed. Temis

26. ENRIQUEZ G. (2006). Control Político como requisito del Estado Constitucional. Criterio Jurídico. V. 6 P. 37-60.

27. ESTRADA A (2003). Las Ramas Ejecutiva y Judicial del Poder Público en la Constitución colombiana de 1991. Bogotá. Ed. U. Externado

28. FERNANDEZ E. (1964). Las Constituciones Colombianas Comparadas. Colombia. Ed. Universal de Antioquia. 


\section{REVISTA VIRTUAL VIA INVENIENDI ET IUDICANDI \\ "CAMINO DEL HALLAZGO Y DEL JUICIO" \\ http://viei.usta.edu.co/ E-MAIL: revistainveniendi@usantotomas.edu.co}

29. FERRAJOLI L. (2003). Pasado y futuro del Estado de Derecho. En Neoconstitucionalismos, editor Miguel Carbonell. España. Ed. Trotta Madrid

30. GARCÍA PELAYO M. (2006), Trasformaciones del Estado Contemporáneo, Madrid. Ed. Centro de Estudios Políticos y Constitucionales.

31. GARCíA PELAYO M. (1991). Estado Legal y Estado Constitucional de Derecho. España. Centro de Estudios Constitucionales. 32. GECHEM C (2005). El Congreso Colombiano a partir de 1991. Temas de Derecho Público 73. Colombia. Ed. U. Externado.

33. GILHODES. Pierre (1993), Sistema de partidos y partidos políticos en Colombia. FESCOL, Fundación para la investigación y el desarrollo de la ciencia FIDEC. P. 69-114.

34. REYES G. (2006). Régimen de bancadas y la prohibición de la doble militancia. Konrad-Adensauer-Stiftung. Colombia Ed. Unión gráfica.

35. HARO R. (2002). Constitución, Poder y Control. México. Ed. UNAM.

36. HELD D. (2005) Un pacto global. España. Ed. Taurus.

37. HELD D. (2007). ¿Hay que regular la globalización?. La reinvención de la política. En La Globalización y el Orden Jurídico. Colombia. Ed. U Externado.

38. HELLER H. (1965). La soberanía, traducción de Mario de la Cueva, México.

Ed. Universidad Nacional Autónoma de México

39. HERDEGEN M. (2007) Estado de Derecho, Responsabilidad Política y buena Gobernabilidad. En revista de estudios socio-jurídicos. V. 9, Julio-Diciembre. №002, p. 11-26. Colombia. Ed. Universidad del Rosario. 


\section{REVISTA VIRTUAL VIA INVENIENIDI ET IUDICANDI \\ "CAMINO DEL HALLAZGO Y DEL JUICIO"}

http://viei.usta.edu.co/ E-MAIL: revistainveniendi@usantotomas.edu.co

40. HERNANDEZ C. (1997) Las ideas políticas en la historia, Colombia. Ed. U Externado.

41. HESSE K. (1983). Concepto y cualidad de Constitución. Derecho Constitucional. España. Centro de Estudios Constitucionales Madrid.

42. HOBBES T. (1993), El Leviatán.España. Ed. Alianza Madrid. p.60

43. HOLGUIN J. (2006). La Reforma de 2003: La Tensión Entre Abrir y Cerrar El sistema Político Colombiano . Colombia. Ed. Uniandes

44. HOSKIN G. y GARCÍA M. (2006); La reforma política ¿la salvación de los partidos políticos colombianos? Bogotá, Colombia. Ediciones Uniandes marzo 2006

45. HOSKIN, G. y GARCÍA, M. (2006). La Reforma Política de 2003 ¿La salvación de los partidos políticos Colombianos. Bogotá. Universidad de los Andes.

46. HUERTA C. (2001). Mecanismos Constitucionales para el Control del Poder Político, México. Ed. Instituto de Investigaciones Jurídicas UNAM.

47. JARAMILLO J. (2005). La reelección inmediata en Colombia, en nueva sociedad 198. 2005 p.16-31.

48. JELLINEK G. (2000). Teoría general del Estado. México Ed. Fondo de cultura económica México.

49. KALDOR M. (2005). La Sociedad Civil Global. Barcelona, España. Ed. Tusquets Editores.

50. KELSEN H. (1995) ¿Quién debe ser el defensor de la Constitución?. España. Ed. Tecnos Madrid. 


\section{REVISTA VIRTUAL VIA INVENIENDI ET IUDICANDI \\ "CAMINO DEL HALLAZGO Y DEL JUICIO"}

http://viei.usta.edu.co/ E-MAIL: revistainveniendi@usantotomas.edu.co

51. LINZ J. (1990). Democracia Presidencialista o Parlamentaria. ¿hay alguna diferencia? Una Revisión crítica. Chile. Ed. Universidad Católica de Chile. Santiago.

52. LOCKE J. (1984), Ensayo sobre el Gobierno Civil. Lecturas Críticas, México 1984. p. 126

53. LOEWENSTEIN K. (1982). Teoría de la Constitución. Barcelona España. Ed. Ariel.

54. MALDONADO H. (2002). El Acertijo de la Reforma Política en Colombia. Monografía de Grado para obtener Magíster en economía. Universidad de los Andes. Bogotá 2002.

55. MAQUIAVELO N. (2003). El Príncipe. Mexico. Ed. Porrúa.

56. MARTÍNEZ L. (1958). Historia de un cambio de gobierno. Colombia. Ed. Santa Fe.

57. MEDELLín P. (2005). De la Crisis de la Representación a la representación de la crisis en Colombia. En La reforma política del Estado en Colombia una salida integral a la crisis. Colombia. Ed. Fondo editorial CEREC.

58. MEDELLíN P. (1988). El Retorno a la política, la gubernamentalización del Gobierno. Colombia. Tercer Mundo Editores.

59. MEDELLíN P. (2000). Gobernabilidad y Globalización en América Latina. España. Colección de documentos Barcelona. 


\section{REVISTA VIRTUAL VIA INVENIENDI ET IUDICANDI \\ "CAMINO DEL HALLAZGO Y DEL JUICIO"}

http://viei.usta.edu.co/ E-MAIL: revistainveniendi@usantotomas.edu.co

60. MEZEY M. (1995). La legislatura, El poder ejecutivo y las políticas públicas. En La democracia Dividida. Compilador James A. Thurber p. 131. Buenos Aires Argentina, Ed. Heliasta.

61. MONTESQUIEU (2007). El Espíritu de las leyes. Mexico. Ed. Porrua.

62. NARANJO V. (2003). Teoría constitucional e instituciones políticas. Colombia.

Ed. Temis.

63. PIZARRO L. (2001), Los Retos de la democracia viejas y nuevas formas de la política en Colombia y América Latina. Bogotá. Ed. Fundación Heinrich Böll.

64. PLATÓN. (1979). La República. Bogotá Ed. Talleres Gráficas Modernas. 65. PLATÓN. (1999). Las Leyes. Diálogos. Madrid. Ed. Gredos.

66. RAMIREZ G. (2005). Límites de la Reforma Constitucional en Colombia. Concepto de Constitución como fundamento de la restricción. Bogotá. Ed. Externado de Colombia.

67. RAMIREZ G. (2007). Transformaciones del constitucionalismo en el contexto de la globalización. En El derecho en el contexto de la Globalización. Bogotá. Ed. U Externado.

68. RESTREPO C. (1995). Constituciones Políticas Nacionales de Colombia. Bogotá. Colombia. Ed. U Externado de Colombia.

69. RESTREPO C. (1988). Síndrome del Presidencialismo en Colombia. Temas de Derecho Público 16. Bogotá. Colombia. Ed. U. Externado.

70. RIVADENEIRA A. (1978). Historia Constitucional de Colombia. 1510-1978, Bogotá. Ed Horizontes. 


\section{REVISTA VIRTUAL VIA INVENIENDI ET IUDICANDI \\ "CAMINO DEL HALLAZGO Y DEL JUICIO"}

http://viei.usta.edu.co/E-MAIL: revistainveniendi@usantotomas.edu.co

71. RIVERA G. (2003). Intervención. Gaceta del Congreso 103. Bogotá, Colombia

72. RONALD. P. y MATTHEW S. (2002). El Potencial desaprovechado del predominio presidencial en Colombia. Presidencialismo y democracia en América latina. Argentina. Ed. Paidos. Buenos Aires.

73. ROUSSEAU J. (1988), El Contrato social. Barcelona. España. Ed. Tecnos.

74. SABINE G. (1965). Historia de la teoría política traducción de Vicente Herrero, México. Fondo de Cultura Económica.

75. SABINE G. (1975). Liberalismo, República y Democracia, en el origen de la Política Moderna. Historia de la teoría política. México Ed. FCE.

76. SABINE, G. (1994), Historia de la teoría política. México. Ed. FCE.

77. SÁCHICA L. (1969), Constitucionalismo Colombiano. Bogotá. Ed. Temis.

78. SAMPER J. (1951). Derecho público interno de Colombia, Colombia. Ed. Biblioteca popular de cultura colombiana Bogotá tomo II.

79. SARTORI G (1980). Partidos y sistemas de partidos. Marco para un análisis. Madrid. Ed. Alianza.

80. SCHMITT C. (1934). Teoría de la Constitución. España. Ed. Alianza Madrid. 81. SECRETARIA DEL CONGRESO 2003 .Gaceta del Congreso 406, 437, 479, 481 de 2002 y 146, 169, 190 de 2003.

82. TOMAS DE AQUINO. Suma Teológica, Biblioteca de Autores Cristinos, Madrid, versión digital 2001.

83. TOMAS DE QUINO (1994). La monarquía. Madrid. Ed. Tecnos. 


\section{REVISTA VIRTUAL VIA INVENIENDI ET IUDICANDI \\ "CAMINO DEL HALLAZGO Y DEL JUICIO"}

http://viei.usta.edu.co/ E-MAIL: revistainveniendi@usantotomas.edu.co

84. VALADÉS D. (1998). El control del poder, México. Ed. UNAM, instituto de investigaciones jurídicas.

85. VALADÉS D. (2000). Constitución y Democracia. México. UNAM, Instituto de investigaciones jurídicas.

86. VALADÉS D. (1994). Constitución y Política. México. UNAM, Instituto de investigaciones jurídicas.

87. VÁSQUEZ A. (1979). El Poder presidencial en Colombia.

88. VIDAL PERDOMO Y VÁSQUEZ CARRIZOSA

89. ZAGREBELSKY G. (2008). El Derecho Dúctil. Madrid. Ed. Trotta.

\section{DOCUMENTOS ASAMBLEA NACIONAL CONSTITUYENTE DE 1991}

1. ASAMBLEA NACIONAL CONSTITUYENTE COMISIÓN TERCERA. Ponencia sobre la función de control político del congreso, ponentes: Álvaro Echeverri Uruburu, Alfonso Palacios Rudas y Arturo Mejía Borda. 1991

2. ASAMBLEA NACIONAL CONSTITUYENTE COMISIÓN TERCERA. Informe sobre la función del control político del Congreso, Ponentes: Álvaro Echeverri Uruburu, Antonio Galán Sarmiento, Arturo Mejía Borda, Luis Guillermo Nieto Roa, Rosemberg Pabon Pabon, Alfonso Palacios Rudas y Hernando Yepes Arcila. (1991)

3. ASAMBLEA NACIONAL CONSTITUYENTE COMISIÓN TERCERA. La función del control político del Congreso, proyecto articulado, Ponentes: Álvaro Echeverri 


\section{REVISTA VIRTUAL VIA INVENIENIDI ET IUDICANDI \\ "CAMINO DEL HALLAZGO Y DEL JUICIO"}

http://viei.usta.edu.co/ E-MAIL: revistainveniendi@usantotomas.edu.co

Uruburu, Antonio Galán Sarmiento, Arturo Mejía Borda, Luis Guillermo Nieto Roa, Rosemberg Pabon Pabon, Alfonso Palacios Rudas y Hernando Yepes Arcila. 1991.

4. ASAMBLEA NACIONAL CONSTITUYENTE COMISIÓN TERCERA Proyecto de acto reformatorio de la Constitución Política, partidos políticos, exposición de

motivos y articulado, Ponentes: Horacio Serpa Uribe, Guillermo Perry Rubio y Eduardo Verano de la Rosa.

\section{SENTENCIAS}

1. CORTE CONSTITUCIONAL DE COLOMBIA. Sentencia C-551 de 2003. Control de constitucionalidad sobre ley de Referendo reeleccionista.

2. CORTE CONSTITUCIONAL DE COLOMBIA, Sentencia C- 496 de 1998. Funciones del presidente de la República como Jefe de Estado, Jefe de Gobierno y Suprema autoridad Administrativa. Control del Congreso de la República.

3. CORTE CONSTITUCIONAL DE COLOMBIA. Sentencia SU-047 de 1999.Obligatoriedad del Precedente Judicial frente a las autoridades administrativas. 


\section{REVISTA VIRTUAL VIA INVENIENIDI ET IUDICANDI \\ "CAMINO DEL HALLAZGO Y DEL JUICIO"}

http://viei.usta.edu.co/ E-MAIL: revistainveniendi@usantotomas.edu.co

4. CORTE CONSTITUCIONAL DE COLOMBIA. Sentencia C- 342 de 2006. reglamenta la actuación en bancadas de los miembros de las corporaciones públicas y se adecua el reglamento del Congreso.

5. CORTE CONSTITUCIONAL DE COLOMBIA. Sentencia C-428 de 1997. Potestad Reglamentaria

6. CORTE CONSTITUCIONAL DE COLOMBIA Sentencia C-449 de1992. concepción de Estado Social de Derecho.

7. CORTE CONSTITUCIONAL COLOMBIANA .Sentencia C-342 de 2006. Control de Constitucionalidad de la Ley de Bancadas.

\section{LEYES}

1. Constitución Política de Colombia de 1991

2. Ley 489 de 1998.

3. Ley $5^{\mathrm{a}}$ de 1992

4. Ley 446 de 1998

5. Acto Legislativo 02 de 2004

6. Ley 649 de 2001

7. Ley 1301994. 


\section{REVISTA VIRTUAL VIA INVENIENDI ET IUDICANDI}

"CAMINO DEL HALLAZGO Y DEL JUICIO"

http://viei.usta.edu.co/ E-MAIL: revistainveniendi@usantotomas.edu.co

8. Acto legislativo 01 de 2003

9. ley 974 de 2005 